Article

\title{
Sustainable Water Use Practices: Understanding and Awareness of Masters Level Students
}

\author{
Dexter V. L. Hunt * and Zeerak Shahab
}

Citation: Hunt, D.V.L.; Shahab, Z. Sustainable Water Use Practices: Understanding and Awareness of Masters Level Students. Sustainability 2021, 13, 10499. https://doi.org/ $10.3390 /$ su131910499

Academic Editor: Peter Driessen

Received: 16 July 2021

Accepted: 17 September 2021

Published: 22 September 2021

Publisher's Note: MDPI stays neutral with regard to jurisdictional claims in published maps and institutional affiliations.

Copyright: (c) 2021 by the authors. Licensee MDPI, Basel, Switzerland. This article is an open access article distributed under the terms and conditions of the Creative Commons Attribution (CC BY) license (https:// creativecommons.org/licenses/by/ $4.0 /)$.
Department of Civil Engineering, School of Engineering, University of Birmingham, Edgbaston, Birmingham B15 2TT, UK; ZXS221@student.bham.ac.uk

* Correspondence: d.hunt@bham.ac.uk

Abstract: Present water consumption in the UK is unsustainable, with increasing societal and environmental pressures driving water stress. Personal use of water is a significant contributor to water demand and considering the number of universities and students in the UK the water use practices therein cannot be ignored. Therefore, this paper aims to deepen the theme of water consumption in the United Kingdom from the point of view of use practices for students. The originality in this research lies in better understanding whether UK Masters level students have a basic awareness of personal water consumption and water pricing and whether they have a preferred approach to reducing their water consumption-through a behavioral change, or through adoption of technologies. Through use of a questionnaire approach applied to five cohorts (2017 to 2021) of Masters level students, the level of understanding and awareness towards their own domestic water use both now and in the future was demonstrated. Key findings suggest that Masters students underestimated their water use by $76 \%$ compared to the average UK national range and that there was an overall preference to adopt water saving technologies rather than changing user behavior ( $40 \%$ vs. $27 \%$ ). The study concludes that it is important to approach water conservation from an SPT perspective in order to achieve meaningful change in water use practices. Qualitative and quantitative research is analyzed in light of theoretical models (i.e., Social Practice and Attitude Behavior Framework ABC) in order to make recommendations for greater societal prominence for this issue through media and education.

Keywords: water use; sustainability; sustainable behavior; sustainability understanding; awareness; perception; attitude; behavior

\section{Introduction}

"We never know the worth of water till the well is dry." - Thomas Fuller

The present use of limited freshwater resources is unsustainable, with water demand rising faster than the available supply. Increased water use globally due to challenges from population growth [1-3], climate change and urbanization will in the not too distant future severely impact society as a whole [4], with increased peaks in water demand, droughts and extreme weather events [5]. Unfortunately, research suggests that water continues to be perceived as a plentiful resource in the temperate climate of the UK [6], with increasing societal expectations and environmental aspirations for its unfettered delivery at the tap [7].

Prior to Brexit the UK moved from tenth highest place in terms of water user per capita, in 2008 [8], to fifth in 2018 [9]. Therefore a 'business-as-usual' approach is no longer sufficient to meet the 'wants' and 'needs' of burgeoning city populations. These will undoubtedly change depending upon who you ask and are likely to take into consideration peoples' priorities for life and their local living conditions [10,11] and, moreover, depend on how aware people are of their own consumption and its impact on current and future generations. Such awareness stems from education and improved knowledge around sustainable consumption, and sustainability more broadly. This starts at a grassroots 
level in early childhood education and continues into higher education. There is an abundance of literature linking sustainable development and its integration with higher education. In the early days, Hopkinson et al. referred to these initiatives as greening the curriculum [12]. Schools and Universities are now perceived as being well-versed in integrating sustainability within their curriculums. However for older cohorts, innovative ways of engaging them, with the topic of sustainable consumption are always being sought. Moreover, it is worth considering how students' acquired knowledge leads to improvements in awareness and ultimately the realization of actual changes in behavior. In other words, is a lack of awareness of the issues at hand still prevalent? Those who lease student properties might suggest that it is, stipulating that students' general use of resources, not least water, can be profligate [13]. Given that in 2018/19 there were over 2.38 million students enrolled in higher education courses in the UK, with almost 1.8 million of these being undergraduate students, and $>585$ thousand enrolled in postgraduate courses (a good number of which are overseas students) their contribution to water demands cannot be ignored. The originality in this research lies in better understanding whether UK Masters level students have a basic awareness of personal water consumption and water pricing and whether they have a preferred approach to reducing their water consumption, through behavioral changes or through adoption of technologies. Additionally, a better understanding of how students engage (or should be engaged) with respect to reducing water consumption, and how to best make clear the value-action gaps [13], is also a focus. A value-action gap is the difference between what people say and what people do (or think they do); in other words, the spaces that occur when the values [14] or attitudes of an individual do not necessarily correlate to their actions. Perhaps an integrative approach to understanding urban sustainability is part of the solution, whereby a combined approach of considering perception, attitude and awareness and their inter-relationship and power over behavior is needed [15-17]. Furthermore, perhaps a more considered approach to how students are engaged with water use behavior, not least when it comes to improving water use efficiency, is required [18].

The frame of previous research is from the bias of individualistic and disconnected understanding of external factors, targeting individuals rather than practices. This paper considers one fundamental step to address this issue by raising the awareness of the next generation of engineers in innovative ways, perhaps sparking them to reduce their demand and perhaps, as engineers, to come up with more radical (i.e., truly transformational) solutions as cities evolve.

Through this research, demand-side management will be informed by perceptions of water use and the level of awareness in older student cohorts who can act as enablers of change [19]. The context is within an MSc postgraduate course in Sustainable Construction and considers outcomes of an innovative method of teaching and data collecting for sustainability over a period of five years (2017 to 2021). Therein it might be assumed that any student, having undergone primary, secondary and tertiary education, would be better informed as to their water using behavior as well as general water pricing, and would have a preference towards ways of reducing their water consumption.

\subsection{Research Aim and Objectives}

This research aims to contribute to a greater understanding of the wider theoretical frameworks and enabling factors influencing student understanding of residential water conservation, to make recommendations for improvements in governance, policy and industry initiatives within the UK context. The principal aim of this project is to add to the growing body of evidence for a novel approach to Social Practice Theory (SPT), for encouraging water conservation practices of students based on wider factors identified using grey literature and survey data.

In order to meet the research aim, the following objectives are defined:

O1 To develop an understanding of the current approaches (including interventions) and issues in residential water conservation within a UK context; 
O2 To identify key behavioral change theories influencing water conservation research;

O3 To develop a simple way to engage MSc students with and measure their perception and awareness of Sustainable Water use practices.

Following from this introductory section, Section 2 outlines the methodological steps undertaken to achieve the aim and objectives, and Section 3 provides a critical review of the literature. Section 4 presents the results of the questionnaire and these are discussed more fully within the discussion presented in Section 5. Recommendations are made in Section 6 followed by concluding remarks in Section 7.

\section{Methodology}

\subsection{Introduction}

This Section describes the methodological steps (M1-M3) undertaken to fulfil the aim and underpinning objectives of this research paper (see Section 1.1 In other words, methodological step M1 allows achievement of Objective O1 and so forth. The development process of the conceptual framework consists of four stages which are presented in Figure 1.

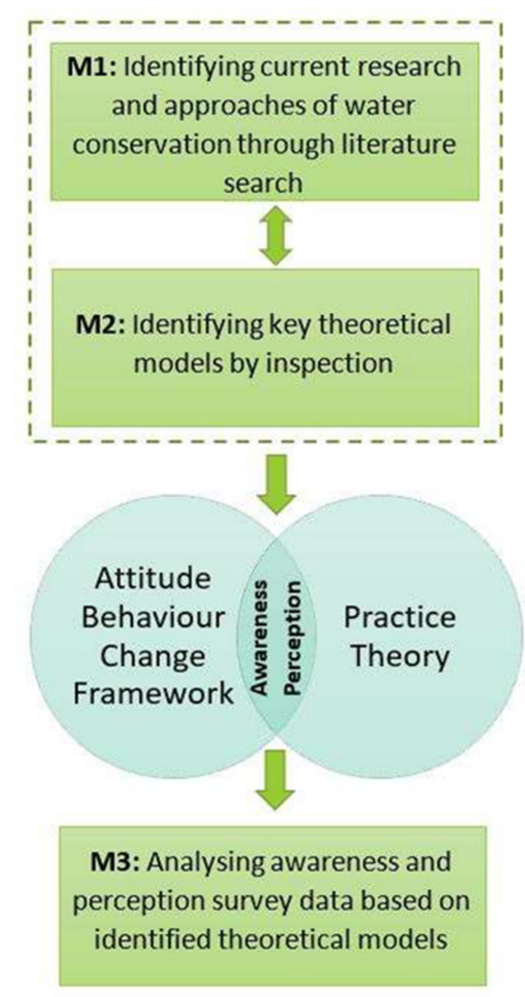

Figure 1. Overview of methodological stages.

\subsection{M1-Identifying Current Research and Approaches to Water Conservation through a Literature Search}

This first methodological step sought to identify literature on current issues and approaches to water conservation in the UK. Sections 3.1-3.4 provide a summary of this. The desk-study included researching online journal articles, books and literature from UK-based water conservation organizations and water industry. Key searches using Web of Science and Scopus were used to generate related articles using multiple combinations of keywords such as 'motivat + barrier" + water + conservat ${ }^{* \prime}$ (39) and 'water + scarcity + U.K.' (37), 'water + perception + U.K.' (60), using filters for the water resources, civil engineering and environmental studies fields (which generated more than 136 studies relevant to the UK context within these and related fields), and snowballing using useful reviews $[5,20]$ to find further studies, focusing on the explicit or more often implied, conceptual theoretical frameworks for the approaches proposed by the authors. 


\subsection{M2-Identifying Key Theoretical Models by Inspection}

This second methodological step sought to identify key theoretical models that influence research into water conservation behaviors through secondary research; this was done through reviewing available literature in the field. Steps M1 and M2 were conducted concurrently to enable summarizing of the drivers of water conservation practices, related factors, and the greater theoretical reasons for their selection (See Section 3.1). Key themes from articles relevant to the research topic have informed the Literature Review and Discussion Chapters of this study. As a result, two key models were identified, as shown in Figures 1 and 3 (See Sections 3.1 and 3.3, respectively).

\subsection{M3-Developing Questionnairre and Analysing Data}

This third and final methodological step sought to evaluate the perception of student domestic water use habits through the use of a survey approach. In so doing this enabled comparison of findings with existing research. Herein a number of multiple-choice questions were selected to investigate water use perceptions and approaches to water conservation, in a time-efficient and simple method so as to encourage student participation. Questions regarding age, gender and country of birth were included to explore the role of demographics in water conservation [21] and to provide baseline parameters to situate the participants' responses within the wider context explored in the literature review.

The survey was developed by the convener of the MSc course in Sustainable Construction (the lead author of this paper) to increase student engagement in and understanding of the course by raising awareness of water conservation practices by comparing perceptions with measured actions and behaviors. This is a long study of one educational group over five years (February 2017 to March 2021 inclusive), with a wide range of backgrounds including MSc students from 50 countries.

As stated previously, the method needed to be simple and it needed to spark interest. Therefore, within the induction session to the module all Masters level students were asked to fill in a 'Water use' questionnaire' consisting of ten questions related to the students' awareness of their water use. These related to:

- Demographics (Q1 to Q3)

- Domestic water using habits (Q4 to Q7);

- Water pricing-bottled and mains water (Q8, Q9);

- Preferences when it comes to socio-technological water efficiency approaches (Q10).

The reasoning behind this streamlined set of questions was to give students a task that will engage them, prompt thought and provide avenues for further discussion and debate during delivery of the course, when the results of the questionnaire (and previous responses) would be presented to them. In particular the aim was to raise their awareness of water use, both as individual students and as a cohort. This included discussions on the underlying habits, which are more broadly defined in this paper in Section 3. Shortfalls of such an approach are further discussed in Section 2.4.

Consenting adult student MSc students $(n=299)$ completed the survey through an online platform embedded within a canvas page. According to the ethical guidelines of the University of Birmingham MSc students were made aware of the voluntary basis of completing the survey and that the data would be anonymized to provide aggregated results. Students were asked to fill in the survey using whatever technology they preferred (see Section 3 for results) at the start of the induction session for the course.

The methodology used within this research consisted of gathering data through use of a questionnaire that contained both closed and open questions. The questionnaire comprised ten questions, which is considered an ideal number for web surveys [22,23]. The questions are summarized as follows:

Q1. What is your gender?

Q2. What is your age?

Q3. In which country were you born? 
Q4. How much water do you use per day?

Q5. Which of the following uses the most amount of water in our homes?

Q6. How many times do you flush the toilet per day?

Q7. How many minutes do you take in the shower each day?

Q8. How much does a $1 \mathrm{~L}$ bottle of drinking water costs in the U.K.?

Q9. How much does $1 \mathrm{~L}$ of mains water costs in the UK?

Q10. Which water saving approach is preferred?

It should be noted that Q4 to Q10 are based on the students' perception (i.e., what they think) as opposed to what they actually do. Wider aspects of learning outcomes for students included improving their understanding of:

- Subjectivity vs. Objectivity, Qualitative vs. Quantitative approaches;

- Differences between perceived behavior vs. actual behavior;

- The use of sustainability indicators, metrics and benchmarks;

- Data collection, analysis and presentation-the trouble with averages;

- The importance of local context and conditions;

- Difference between 'needs' and 'wants';

- How to develop sustainable strategies for reducing Water consumption;

\subsection{Limitations of Survey Approach}

The approach could be criticized for measuring (in a very shallow way) aspects that are very broadly defined (i.e., knowledge/awareness). In addition, students could have been asked more in-depth questions about their knowledge of other aspects relating to water use and its provision: virtual water (i.e., its use in agriculture and industry), water supply issues, access to water, sewerage (a significant consumer of potable water), energy/water/food nexus, and possible water re-use amongst other aspects. However, trials of a much longer questionnaire which included some of these aspects led to students disengaging from the process after ten questions, hence the shortened version was adopted. This was an important finding from a pedagogical point of view. As would be expected, these other aspects do form significant contributing parts to the MSc course and are covered within the taught material. The survey approach opened up avenues for further discussion on these topic areas.

Limitations of the survey also lie in that it was an online survey non-incentivized for accuracy, with the omission of open-ended questions due to time and cost implications. It is also recognized that reported perceptions could be aspirational rather than actual perceptions [24]. As a follow up study, all students were encouraged to measure their actual (rather than perceived) water use, however very few undertook the self-monitoring process, indicating that digital interaction was preferable to self-measurement, which was harder to motivate or, as some suggested, impractical to implement. This again has implications for the theories presented. Therefore, there was no comparison with independent measurements of individual water use and available estimates had to be used for comparison. Results presented in Section 3 are not tested for statistical significance between different categories, and require empirical testing of a larger sample to ascertain this. That said, some questions are filtered to ascertain the influence (or not) of age, gender, country of birth and year of study.

Given the background this student sample might also be assumed to be rather biased, not least given it is from one university. The choice of a more longitudinal study was undertaken to remove some of this potential bias, however again it is from a single university perspective and hence follow up studies are advocated using students at other universities across the UK and overseas.

\section{Literature Review}

The methodological approach for undertaking the Literature review has been detailed in M1 (Section 2.2). 


\subsection{Theoretical Background for Current Water Conservation Research}

This Section traces the theoretical frameworks underpinning current water conservation research, exploring contextual evidence for their popularity and highlighting the need for novel approaches for adoption of more effective water conservation interventions.

Difficulty in constructing or modifying water supply systems has led to an 'increasingly noticeable bias towards anthropocentric demand-side aspects of water management research' (Pearce, Desai and Barr, 2013, p. 961) [25]. Most of the current research into water conservation that informs policy instruments is focused on identifying factors that influence individual behavior in the form of motivational factors and barriers [26], such as the Reasonable Person Model [27]. These models, researched widely in environmental psychology, have proposed a causal link between individual behaviors and pro-environmental actions, prominently citing Ajzen's Theory of Planned Behavior (TPB) which suggests a linear and rational decision-making process behind individual behavior [28]. This is based on exogenous drivers such as product information and price or relies upon individual attitudes and values $[19,29]$, sometimes referred to as the Attitude, Behavior Change (ABC) framework [30]. Table 1 shows examples of interventions relying on such an approach. Therein each Intervention is allied to either a Reasoning Pathway (RP) or Intuition pathway (IP), as outlined in Figure 2.

Table 1. Examples of interventions using an ABC framework approach.

\begin{tabular}{|c|c|c|}
\hline Intervention & Description & Reference \\
\hline $\begin{array}{l}\text { Socio-technological } \\
\text { (RP) }\end{array}$ & $\begin{array}{l}\text { Dividing into technological structures, economic } \\
\text { strategies and socio-political methods }\end{array}$ & [31-33] \\
\hline $\begin{array}{c}\text { Priced } \\
\text { Non-price based } \\
(\mathrm{RP})\end{array}$ & $\begin{array}{ll}- & \text { Taxes and subsidies } \\
- & \text { Water charges } \\
- & \text { Regulation } \\
- & \text { Technology } \\
- & \text { Information provision }\end{array}$ & {$[34,35]$} \\
\hline \multirow{3}{*}{$\begin{array}{l}\text { Push-Pull nudge } \\
\text { (IP) }\end{array}$} & $\begin{array}{l}\text { Pushing change (mandating technological efficiency } \\
\text { through design codes) }\end{array}$ & \multirow{3}{*}[34,36-40]{} \\
\hline & $\begin{array}{l}\text { Pulling change (incentivising the adoption of } \\
\text { smart meters) }\end{array}$ & \\
\hline & $\begin{array}{l}\text { Nudging change (using frames for encouraging water } \\
\text { conservation behaviours) }\end{array}$ & \\
\hline
\end{tabular}

An ever-increasing list of contextual factors, such as material objects and infrastructure, may account for the identified 'value-action gap' [41] re-establishing cause-effect relationships that can be leveraged through interventions, as perceived to be suitable by policymakers [42]. Value-action gaps in the field of water conservation are an evident and growing concern. However, while there is much 'ideological support for water conservation' there is much less practical evidence of its implementation [43]

Behavioral economics gained popularity within the UK government and internationally around ten years ago, not least within the institution of the Behavioral Insights Team (BIT). BIT widely uses 'nudges', as they are seen as easily adaptable, evidenced and relatively cheap, requiring little if any, change to current conservation policy [44]. 
Reasoning Pathway

Rationale: Change the precursors to behavior (e.g., knowledge, awareness, attitudes, motivations).

\section{\#2 Incentivizing Behavior}

Extrinsic Incentives

(e.g. financial, regulatory, social); Intrinsic Incentives (e.g., values, desires)

\#1 Promoting Awareness \& Concern

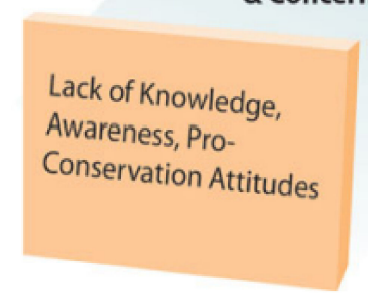

\section{Conservation}

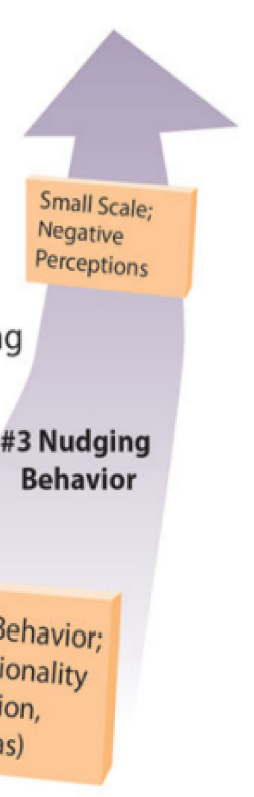

Figure 2. Model based on the ABC for guiding conservation policy [40]).

Using behavioral economics to inform policy has become synonymously popular with the concept of 'nudge' proposed by Thaler and Sunstein in 2009 [39], which aims to 'describe ways in which individuals can be benevolently influenced (nudged) when making decisions.' [44]. Behavioral nudges can be implemented through a variable combination of 'social comparisons, defaults, message frames, [or] commitment devices' [40].

Key influences identified from existing studies and adopted by policymakers can be best described by the framework proposed by Reddy et al. in 2017 [40], who collated models readily available in other fields for guiding conservation policy. This was based on the premise that individual behavioral change will lead to a conservation solution as shown previously in Figure 2.

Much psychological research has been undertaken to examine the five broad causes of residential water conservation behaviors: attitudes, beliefs, habits or routines, personal capabilities, and contextual factors [45]. For MSc students it might be expected that achieving \#1, certainly with respect to knowledge, is a given, and yet if awareness, or more importantly concern (see Section 3.4) are lacking, the case for achieving \#2 may be problematic. In other words, a student might be eminently aware that they spend $>10 \mathrm{~min}$ in the shower but simply not care unless there are incentives (e.g., financial or other) to change the way they think and behave. Alternatively, \#3 (nudging behavior) could be adopted amongst students at university, making a behavioral change easier and more intuitive rather than relying upon a reasoning pathway.

\subsection{Criticism of Current Water Conservation Interventions}

Aside from considerable criticism of 'nudge' for its libertarian paternalism, Lodge and Wegrich [46] demonstrate the paradox between nudge's assumed bounded rationality of the policy-maker and its ability to identify choices, which 'pretends to be evidence-based in order to find seemingly low cost, high-intelligence measures' due to various political and financial factors, with a tendency towards confirmation bias [46]. In other words, focusing on an $A B C$ paradigm reveals a deeper hope within government to make individualistic choices a sufficient means of enabling a meaningful change in water demand [30]. Other academics highlight the inherent dichotomy between water commodification and water conservation efforts [25]. They further suggest that the structure of the UK's neoliberal capitalistic society enables dystopian messages, perpetuating ideas of unlimited water availability as 
an urban lifestyle utility while implicitly portraying end-users as having an uncontrolled demand despite facing climate change issues. As argued by Shove, Pantzar and Watson in 2012 'the ABC framework is not only a theoretical, but also a political position which features individuals as both the problem and the solution, minimizing the government's role in sustaining 'unsustainable institutions, conventions and ways of life' [47]. Thus, contrary to the bounded rationality of the $A B C$ paradigm, it is suggested that policies themselves are an emergent effect of the system they seek to influence [48]. Debates within the water industry arising from water companies' responses to Ofwat's tough regulatory measures [49] and the acceptance of such aspects as water justice (Shrimpton et al., 2021), serve to demonstrate the existence of complex dynamics sustaining and influencing, both internally and externally, the current approach. Further discussions on these are beyond the scope of the current study.

In summary, many studies are price-focused [50], or investigate changes in perception due to extreme events [51]. Often these approaches are undertaken from a perspective of finding causal links that support the $\mathrm{ABC}$ framework [5,52]. However, a considerable body of water conservation literature does not link back to a wider theoretical framework that some argue is required for encouraging water conservation practices [53]. These include the use of price signals where it is presumed that a rational reduction in water use occurs for those, in this case students, paying or perceiving a higher price for water [54]. However, in reality this may not occur depending on how water is both valued and costed.

\subsection{Social Practice Theory (SPT)}

There is a growing body of literature $[42,44,55-59]$ towards a Social Practice Theory (SPT) approach, where Social Practice can be understood as formed habits that require recurrent, consistent reproduction, [48]. Herein, a need to move away from elucidating individual coherence to integrating wider and more complex ways of understanding conservation behaviors of students is suggested [53,60]. Additionally, social norms of students are advocated as a 'promising instrument' for improving water conservation behavior, not least in the UK $[34,60]$. More specifically, others propose that individual choices cannot be relied upon solely to produce meaningful changes in society [55,61]. This follows from the work of Southerton et al., [62] who suggested that individualism, salience and variability can be overcome through creating new social norms and a culture of water conservation [62]. Indeed, this is the unique advantage of using SPT in catapulting 'social life' to the foreground [57] through emphasis on the 'socio-technical structures' as the basis for analyses [56].

SPT enables a different view of the problem, rather than simply meeting existing needs of students. Reframing the practices of water conservation through their relative meanings (i.e., ideas, aspirations, symbolic meanings), materials (i.e., objects and infrastructures such as investment and technological advancements) and competencies (i.e., multiple forms of the conventional understanding of the practice, skills to execute, practical knowledge) enable a much wider framework of understanding than currently offered [48]. Studies suggest that policymakers support an SPT approach due to it being risk-averse [44]. However, more research is needed to overcome any perceived difficulties when using it as a central model for developing policies and standards. Subsequent development of the approach by Satur and Lindsay [43] enabled more footholds to be secured for effective future interventions (Figure 3). 


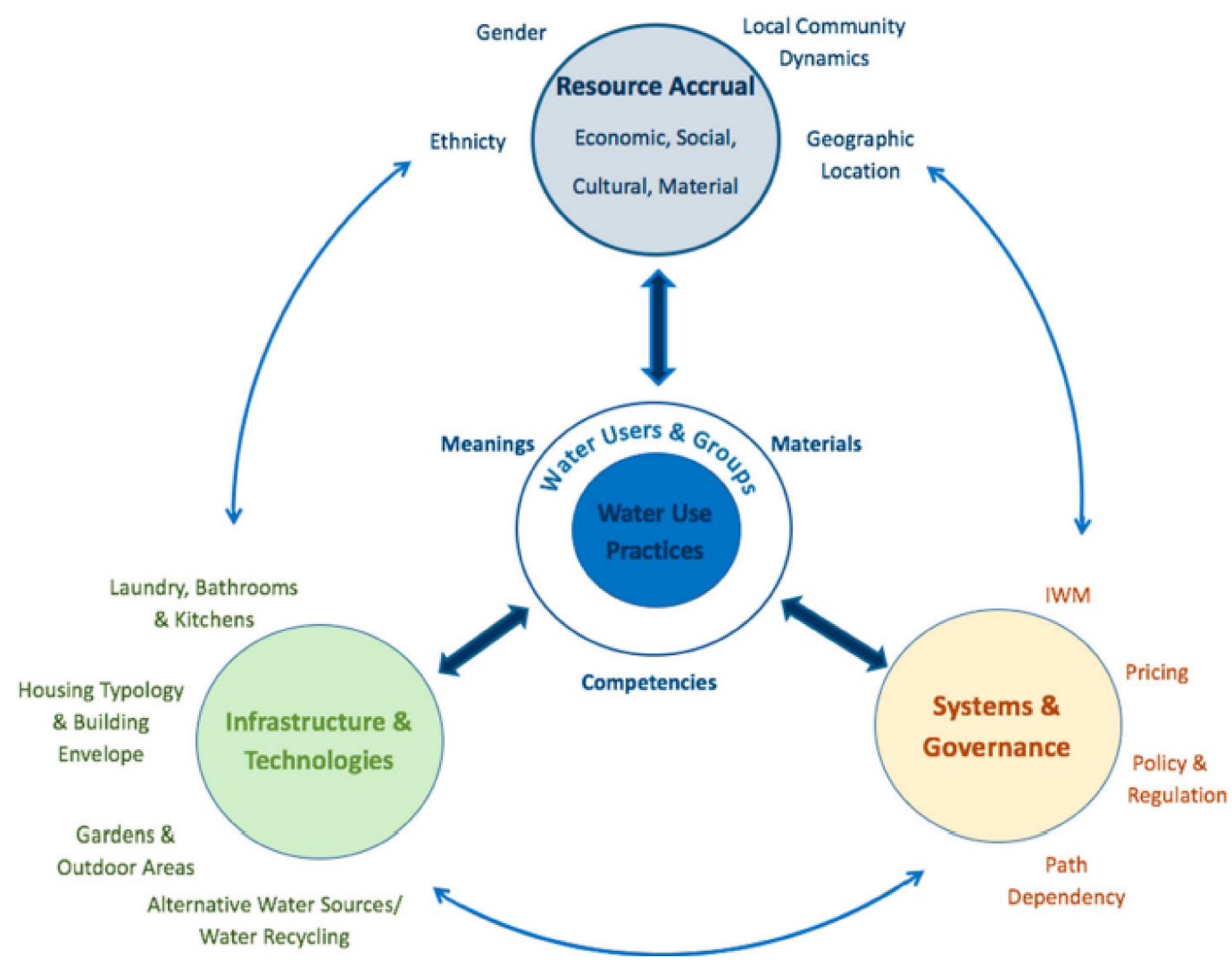

Figure 3. Social Practice Theory (SPT) based model for investigating water use practices [43].

SPT suggests individuals have less autonomous power in changing their water use behavior due to a range of widely accepted norms and standards [60], This is different from $\mathrm{TPB}$, where behavioral achievement is very much dependent on student motivation (i.e., intention) and ability (i.e., behavioral control). Hence the role and efficacy of water pricing, a driver for the $\mathrm{ABC}$ approach, is likely to be minimized in real life when considering the SPT case. While much of the literature focuses on aggregate views of water consumption, very few studies look at the individual student; this includes pricing level and consumption perception inaccuracies, particularly in the UK. This study aims to address this gap in knowledge for postgraduate MSc students, and contribute to the growing support for SPT to aid water conservation efforts.

\subsection{Awareness and Perception}

Awareness is the state or level of consciousness where sense data can be confirmed by an observer. On the other hand, perception is the organization, identification, and interpretation of sensory information, a process by which organisms interpret and organize sensation to produce a meaningful experience of the world [63]. An individual may be eminently aware of the need to conserve water, and they may interpret or perceive that their water using behavior is very good, yet this may be substantially different from reality. Over the last 40 years, a move away from simple information campaigns towards enabling wider societal prominence and awareness has been sought within water conservation literature. Message framing therein has been shown to be highly influential on reducing household water use [64]. However, this awareness element is often minimized or inappropriately explored within the literature [65].

Hence this current study will address this gap, enabling the effectiveness of the current awareness campaigns and programs for water conservation to be evaluated. It might have been expected that the survey of students in a Sustainable Construction course would show a higher level of general awareness than existing studies of general public groups, 
not least because previous research has shown that education affects our actions, including those related to the environment [66]. Although set against a prevalent misconception of abundant water resources in the UK $[6,67,68]$ and hence very low awareness of or belief in water scarcity, it has been shown to manifest in unchecked water use practices $[6,64]$, including for students. Unfortunately, there is much evidence for the existence of stronger relationships between individuals' perceptions of climate change with energy-related issues 'more than [with] water- or food-related issues' [69]. Water awareness and appreciation seem to only temporarily improve in situations where supply is restricted (i.e., during droughts). Therefore, improving awareness while changing habits and/or lifestyles is considered to be a key factor in improving water conservation $[4,53,62]$.

This paper contributes to assessing the perception of practice-based end-uses [70], including residential high water use activities, awareness of water use habits and consumption, and perceived water prices. Tracking the perceptions of water use habits of students allows for future comparison of the highly educated groups considered in this paper with more general public studies, allowing investigation of societal prominence and awareness of water use habits. Students' preferred strategies for water demand management, as in whether they prefer a technological efficiency or user behavior change (curtailment) view, [4] are also investigated and analyzed in the context of underlying theoretical frameworks.

\section{Results}

The results are presented descriptively in this section with discussion in light of theories laid out in Section 5.

\subsection{Completion Rate, Time for Completion and Device Preference}

Over a five-year period (2017 to 2021), five cohorts of students (600 students in total) were asked to fill in the questionnaire. Incomplete responses were subsequently excluded, meaning that 299 fully completed responses could be analyzed, corresponding to a completion rate of $50 \%$. The average time for completion was 5 min $11 \mathrm{~s}$, well within the 10 min threshold suggested to maximize responses [23] and minimize dropout rates and fatigue effects [22].

Mobile phones, at 52\% (156 responses), were the most preferred device used to complete the questionnaire followed by Desktops at 40\% (118 responses). Tablets, at $8 \%$, (25 responses) were the least preferred device.

Tablets had the highest rate completion rate of $63 \%$, followed by mobile at $60 \%$. Desktops had the lowest completion rate at $40 \%$.

Desktops had the fastest average time to complete ( 3 min 59 s) followed by mobile (5 min $42 \mathrm{~s}$ ) and Tablets, which had the slowest average time to complete (7 $\mathrm{min} 46 \mathrm{~s}$ ).

\subsection{Demographics}

Questions 1 to 3 (Q1 to Q3) were related to the demographic of the student cohort.

\subsubsection{Q1-Gender}

When considering the 5 years average, 186 respondents (32\%) identified as females and $113(68 \%)$ identified as males. This shows the predominance of males undertaking engineering courses, a trend consistent across all five years with only mild fluctuation from $43 \%$ in 2017 to $34 \%$ in both 2020 and 2021. That said, the number is above the $35 \%$ female representation of STEM students in higher education as reported by UCAS data provided by HESA in 2017/18 [71].

\subsubsection{Q2-Age}

Almost three quarters of this student group (220-74\%) were aged between 18 to 24 , the majority of the remaining quarter $(24 \%)$ were aged 20 and 29 years, 12 students were aged between 30 and 39 years and 11 respondents were over aged 40 years and over. 


\subsubsection{Q3 - Country Where Respondents Were Born}

A diverse range of countries, fifty in total, were represented on this MSc course over the five-year period. The top 25 are shown in Figure 4.

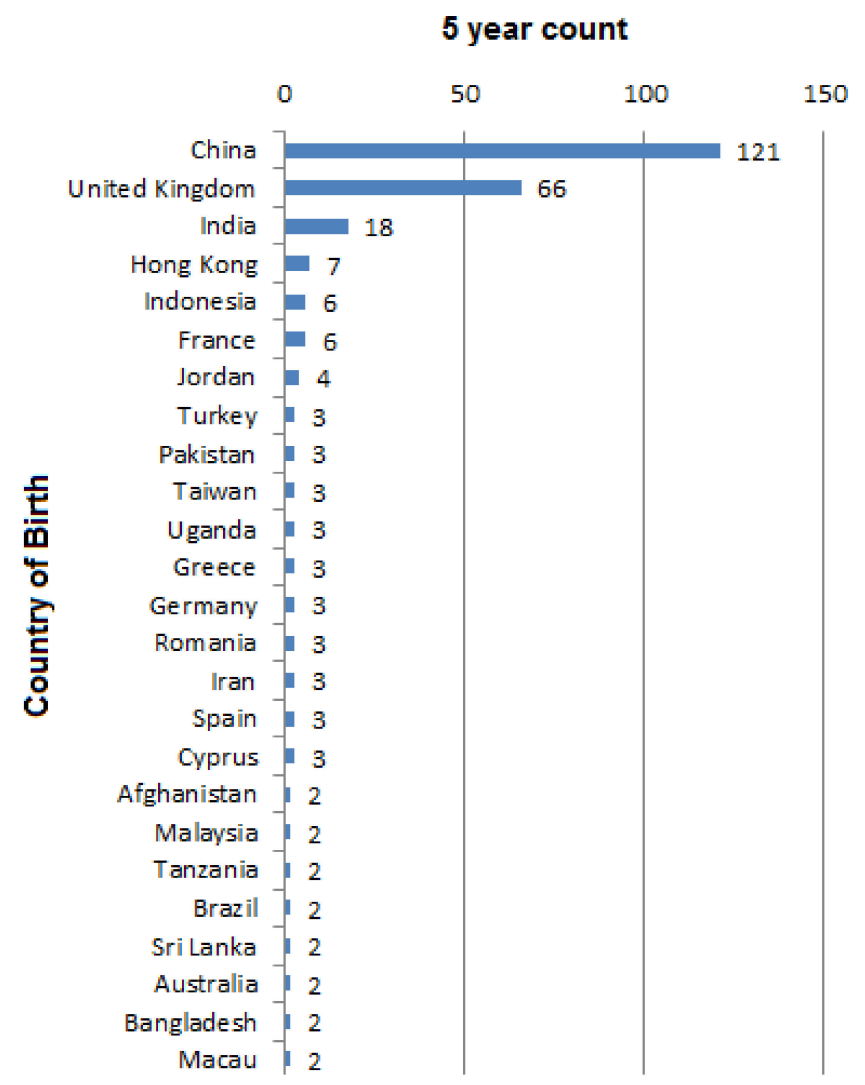

Figure 4. Hierarchy (Top 25 shown) of countries where respondents were born.

This exemplifies the truly global community within the University of Birmingham. On average, the most represented country was China at $40 \%$ (121 students) followed by the UK at $22 \%$ (66 students) and India at $6 \%$ (18 students). The remaining 25 countries not shown in figure each had one student represented during the five years considered.

The three demographic variables considered here allowed the data to be filtered accordingly to see if the answers were influenced by gender, age or country of birth. The data could also be filtered by year to see if different yearly intakes influence understanding and awareness.

\subsection{Water Consumption}

Questions 4 to 7 (Q4 to Q7) were related to student water consumption and their awareness and understanding of how much water they used and which water uses demanded the most water.

\subsubsection{Q4-How Much Water Do You Think You Use per Day}

Students were asked to estimate their own 'domestic' water consumption. Table 2 shows results for the whole cohort of students. To help to identify demographic nuances, additional breakdowns are given for the top three most common countries of birth. Considering responses from all students over the five years it can be seen that the average consumption of water is estimated to be $35 \mathrm{~L} / \mathrm{p} /$ day. This is $30 \%$ lower than the $50 \mathrm{~L} / \mathrm{p} /$ day recommended by the UN and $76 \%$ less than the $146 \mathrm{~L} / \mathrm{p} /$ day suggested for domestic water consumption in the UK [54]. 
Table 2. Students estimated Water demand (filtered by country).

\begin{tabular}{ccccc}
\hline \multirow{2}{*}{$\begin{array}{c}\text { Water Consumption. } \\
\text { (L/person/day-L/p/day) }\end{array}$} & $\begin{array}{c}\text { Cll } \\
\mathbf{( 2 9 9 )}\end{array}$ & $\begin{array}{c}\text { China } \\
\mathbf{( 1 2 1 )}\end{array}$ & $\begin{array}{c}\text { UK } \\
\mathbf{( 6 6 )}\end{array}$ & $\begin{array}{c}\text { India } \\
\mathbf{( 1 8 )}\end{array}$ \\
\cline { 2 - 5 } & 7 & 6 & 0 & 0 \\
$1-5$ & 73 & 54 & 4 & 3 \\
$5-10$ & 56 & 28 & 8 & 4 \\
$10-50$ & $\mathbf{9 3}$ & 22 & $\mathbf{2 6}$ & $\mathbf{8}$ \\
$50-100$ & 36 & 5 & 11 & 2 \\
$100-150$ & 23 & 3 & 12 & 0 \\
$150-200$ & 7 & 1 & 3 & 1 \\
$>200$ & 4 & 2 & 2 & 0 \\
\hline Average (L/p/day) & 35 & 16 & 80 & 31 \\
\hline
\end{tabular}

Bold shows highest number of count within cohort.

When looking at the UK cohort in isolation it can be seen that this average value is $80 \mathrm{~L} / \mathrm{p} /$ day, some $45 \%$ lower than the average UK value and in line with recommended best practice suggested by the voluntary Code for Sustainable Homes-level 6 [72]. Interestingly, this is also in line with the findings of a recent report that suggested British householders underestimated their household water usage by half [73]. Overall, it can be seen that 49 students out of 66 (i.e., $74 \%$ ) underestimate their water use compared to the national average of their country of birth (i.e., the UK).

The average for students born in China is lower still at $16 \mathrm{~L} / \mathrm{p} /$ day, very close to the value of $15 \mathrm{~L} / \mathrm{p} /$ day suggested as the minimum quantity of water to survive [54]. More importantly, it is lower by $86 \%$ than the $104 \mathrm{~L} / \mathrm{p} /$ day $\left(38 \mathrm{~m}^{3} /\right.$ year) suggested when assessing water efficiency measures adopted for China [74]. Overall, it can be seen that 115 students out of 121 (i.e., $95 \%$ ) underestimated their water use compared to the national average of their country of birth (i.e., China).

The average for students born in India is slightly higher at $31 \mathrm{~L} / \mathrm{p} /$ day. However, this is lower by $77 \%$ than the benchmark domestic value of $135 \mathrm{l} / \mathrm{p} /$ day suggested for minimum service delivery by the Ministry of Housing and Urban Affairs [75]. Additionally, it is $73 \%$ less than the value of $117 \mathrm{~L} / \mathrm{p} /$ day suggested for rural semi-arid areas, although only $44 \%$ less than the value of $55 \mathrm{~L} / \mathrm{p} /$ day suggested for rural areas by the Ministry of Housing and Urban Affairs [75,76].

In 2018, when assessing global domestic consumption values in 198 cities in 49 countries the lowest and highest values, respectively, were $14 \mathrm{~L} / \mathrm{p} /$ day in Mbarara, Uganda and $538 \mathrm{~L} / \mathrm{p} /$ day in Denver, CO, USA [77].

Figure $5 \mathrm{a}, \mathrm{b}$ show that overall choices within the whole cohort of 299 students were relatively unaffected by the age or gender of students, respectively, with only minor changes being identified. The same was true of the years 2017 to 2021 . 

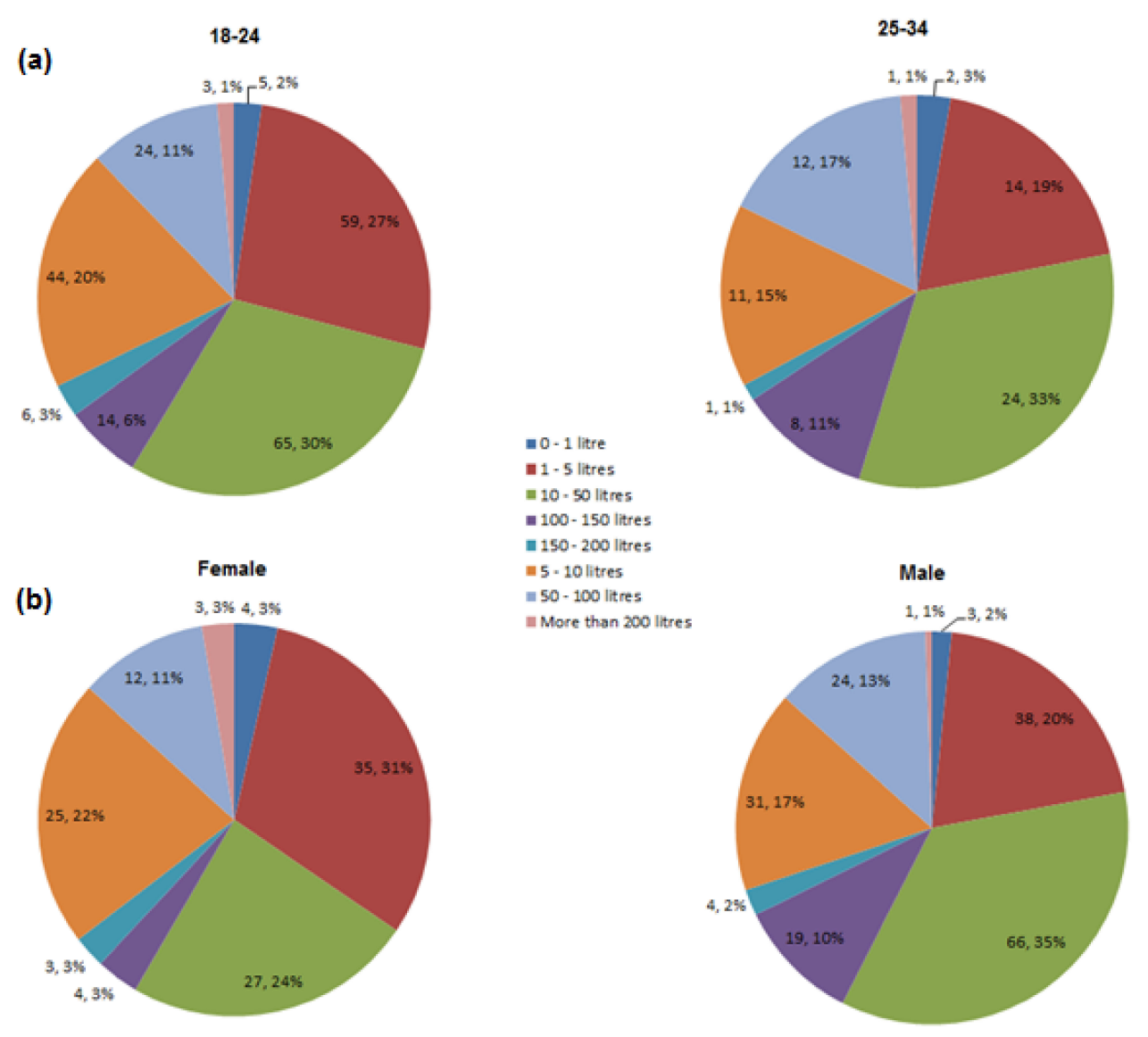

Figure 5. Influence of (a) age and (b) gender on perceived domestic water use.

4.3.2. Q5-Which of the following Do You Think Uses the Most Amount of Water in Our Homes?

Students were asked to identify, from a list of eight domestic water using technologies, those which used the highest amount of water. Figure 6 shows the results, from which can be seen that the highest water using technology, with 133 votes (45\%), was reported to be showering. Showering is considered by many authors as the highest water consuming activity within the home [78-80]. Bathing, Toilet Flushing and Washing Machine gained broadly similar numbers of votes (44, 42 and 37, respectively), fewer combined votes than showering. These top four water uses again conform to findings from the literature. Hence it appears that Masters level students are well-informed when identifying where high water usage occurs in the home.

When filtering against gender, $52 \%$ of females considered showering as the highest water using technology, compared to $40 \%$ of the males. This shows that a higher\% of females than males consider showering as the highest water using technology.

When looking at the influence of place of birth on choice of highest water using application in Figure 7, it can be seen that in all three most numerous birth places identified, showering is considered to have the highest water use, with China having the highest $\%$ and the UK having the lowest. Additionally, no UK student considered drinking as the highest water use in the home and no Indian student indicated drinking water, dishwasher or garden watering as the highest water use. 


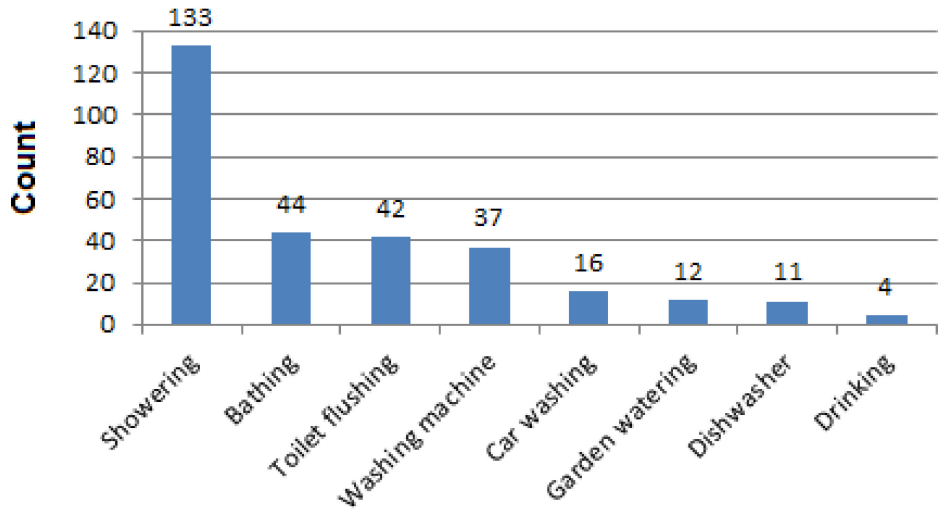

Water Use

Figure 6. Students' identification of the highest water use application in the home.

All

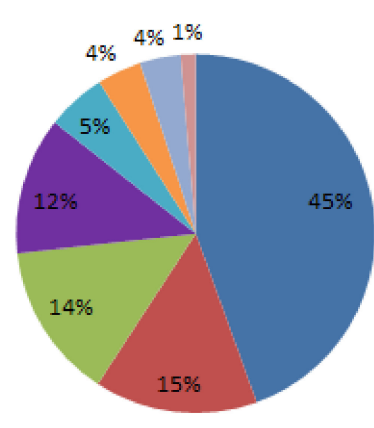

China

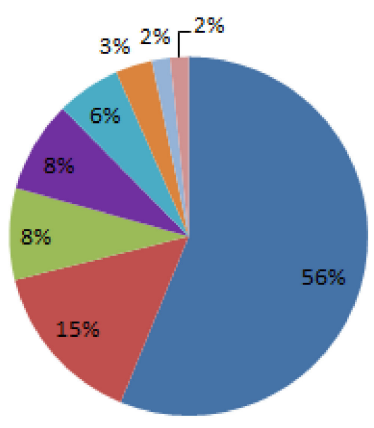

United Kingdom
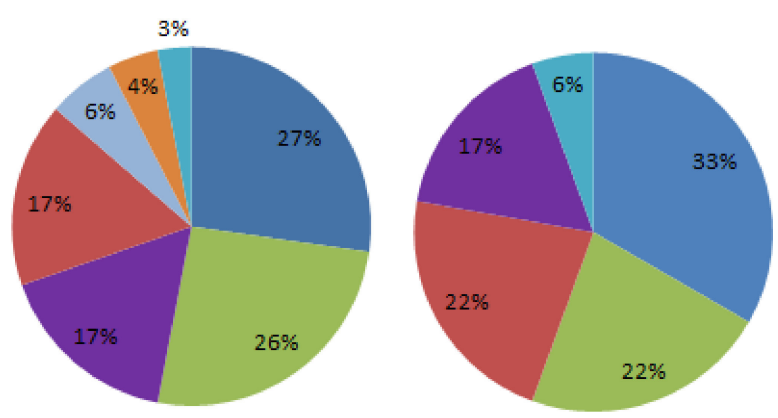

Figure 7. Influence of place of birth on choice of highest water using application.

\subsubsection{Q6- How Many Times Do You Think You Flush the Toilet per Day?}

Students were asked to identify how many times they thought they flushed the toilet per day. It can be seen from Figure 8 that the most popular choice for estimated toilet flush count is five, when considering all years. This is unchanged when filtering for year, place of birth, gender and age group 18 to 24 . However, when filtering for age group 25 to 34 the most popular choice was changed to four flushes per day.

This value is in line with the average value of four to five flushes per day reported in the literature [78-80], and therefore suggests that on the whole students were aware of the daily number of flushes they made. 


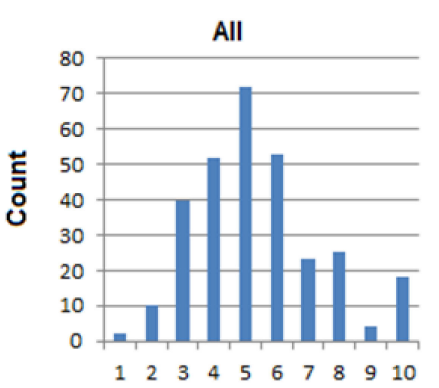

Number of Flushes

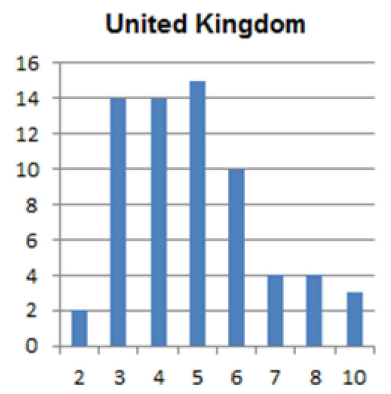

Number of Flushes

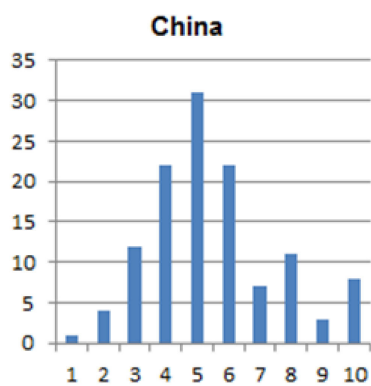

Number of Flushes

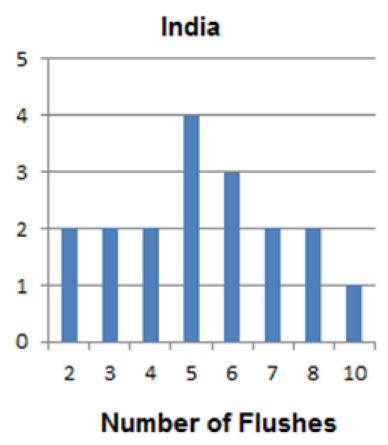

Figure 8. Estimated Toilet flush count per day.

\subsubsection{Q7-How Many Minutes Do You Think You Take in the Shower Each Day?}

Students were asked to identify how many minutes they think they spend in the shower per day. It can be seen from Figure 9 that the most popular choice at 173 counts ( $58 \%$ of cohort) was $10 \mathrm{~min}$ or more when considering all years. This was relatively unchanged when filtering for place of birth, gender, age group and year of study.

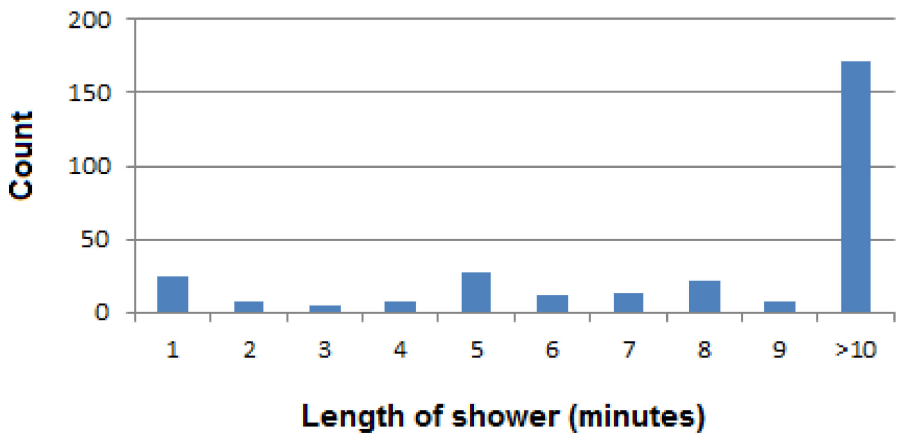

Figure 9. Self-estimated shower lengths of students.

Strikingly, in the Water UK survey only 3\% of respondents suggested they had a shower of $10 \mathrm{~min}$ or more. This is a most striking result that shows there is a high level of uncertainty between what we think we do and what we actually do. Moreover, this value suggests that on the whole students tend to have longer showers than the 2 to $6 \mathrm{~min}$ suggested through the results of the Water UK survey [73], and significantly more than the 4 min often specified by water providers in times of drought.

When considering that the flow rate of a typical shower is $12 \mathrm{~L} / \mathrm{min}$, a $10 \mathrm{~min}$ shower equates to $>120 \mathrm{~L} / \mathrm{p} /$ day if one shower is taken per day. This is not an insignificant amount of water, and only $25 \mathrm{~L}$ less than the total individual daily water consumption value benchmark at Level 4 of the Code for sustainable Homes [72].

Further investigation of the data showed that 155 students (i.e., $53 \%$ of cohort) who previously suggested they took $>10$ min showers also suggested (by way of answer to Q4) that their overall water consumption would be less than $100 \mathrm{~L}$ per day. This shows that over half the student cohort are unaware of how the two are interrelated. That said, some 85 students (i.e., $28 \%$ of cohort) suggested they both took $>10$ min showers and considered showering as the highest water use (Q5).

Overall, this shows that a quarter of students are aware that showering does have an impact on water demand, but that they are less able to identify exactly how much it contributes to overall daily water demands. This was not impacted by place of birth, gender, or age. 


\subsection{Water Pricing}

Q8. How much do you think a $1 \mathrm{~L}$ bottle of drinking water costs in the UK?

Q9. How much do you think $1 \mathrm{~L}$ of mains water costs in the UK?

Students were asked to identify the cost of both mains and bottled water (Figure 10).

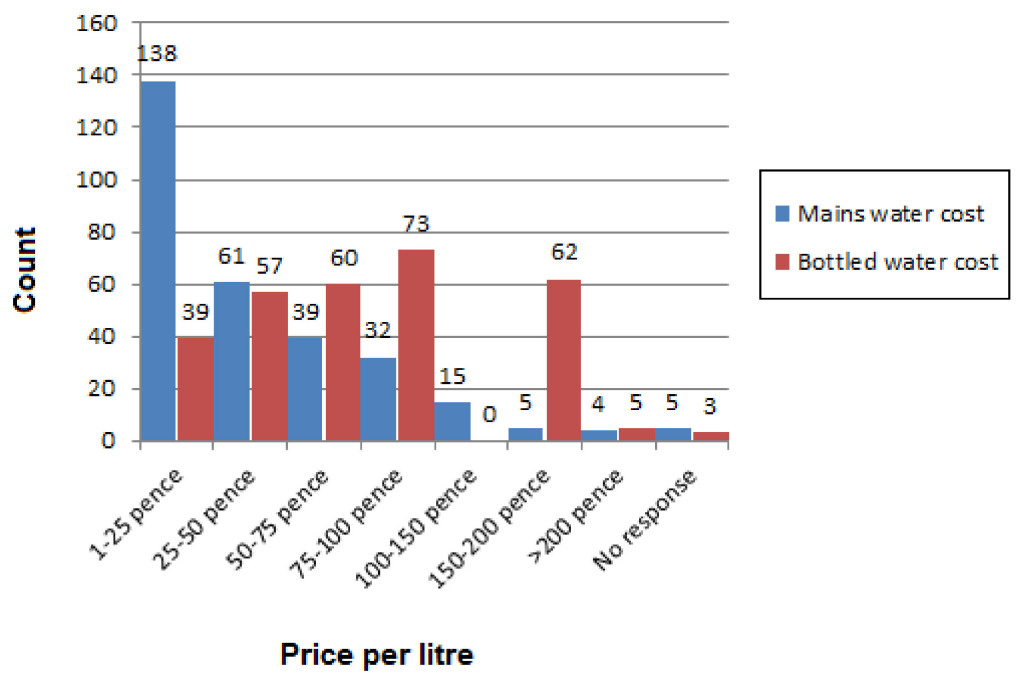

Figure 10. Estimated costs of bottled and mains water.

Mains water price perception at the lowest range (i.e., 1 to 25 p) was chosen by $46 \%$ of the student cohort, much higher than surveys of the general public, while only $13 \%$ MSc students chose the lowest cost option [81].

Herein it can be seen that only 25 students ( $8 \%$ of the cohort), from various locations, thought mains water was more expensive than bottled water (data above solid black line in Figure 11), meaning that 274 students, $92 \%$ of the cohort (data below solid black line in Figure 11) were aware that bottled water in the UK is more expensive than mains water.

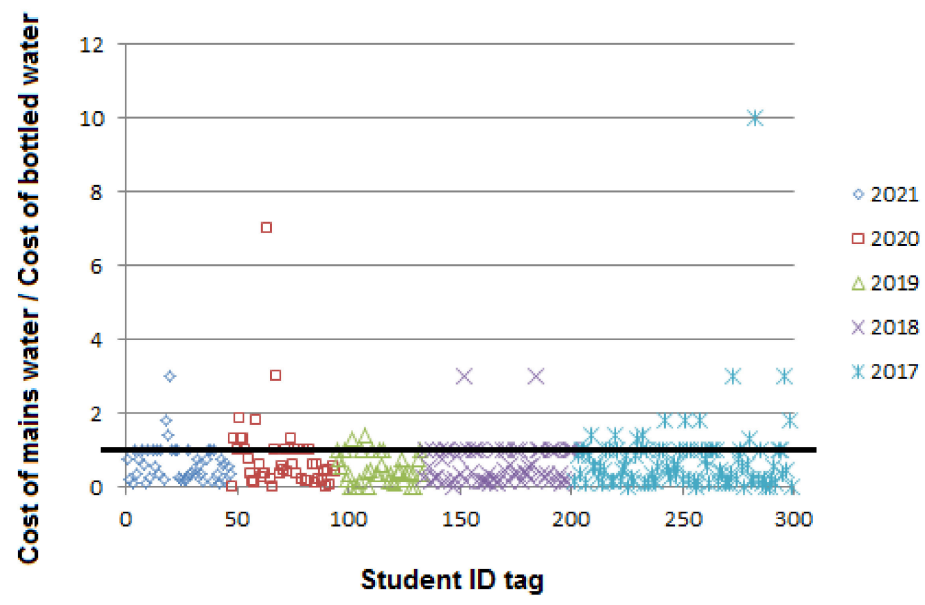

Figure 11. Cost of mains water/cost of mains water for each student.

The average price for bottled water in the UK from this survey came out as $83 p$ as compared to $43 \mathrm{p}$ for mains water, the former being in line with typical values for bottled water, the latter being 1000 times more than the typical value for mains water. The results suggest that on average students believed mains water was around half the price of bottle water. The actual price of UK mains water is typically much less (i.e., up to $500 \times$ less) than bottled water. However, the latter can vary significantly according to brand (e.g., own brand vs. popular brands), location of purchase (e.g., Tesco to Asda), quantity bought (e.g., 
a single $500 \mathrm{~mL}$ bottle to $10 \times 1 \mathrm{~L}$ multipack bottles) and any store promotions that may be in place. A quick search of online superstores revealed the prices shown in Table 3.

Table 3. Cost of Bottled water in UK (online superstore prices, July 2021).

\begin{tabular}{|c|c|c|c|c|c|}
\hline \multirow{2}{*}{ Supplier } & \multicolumn{5}{|c|}{ Cost $(£ / L)$} \\
\hline & Own Brand & Volvic & Highland Spring & Evian & Nestle (Pure) \\
\hline Tesco & $0.34^{\mathrm{d}}$ & $0.46^{\mathrm{c}}$ to $1.0^{\mathrm{a}}$ & $0.4^{\mathrm{a}}$ to $0.5^{\mathrm{b}}$ & $0.9^{\circ}$ to $1.3^{r}$ & $0.28^{a}$ \\
\hline Lidl & - & - & - & - & - \\
\hline Aldi & $0.24^{\mathrm{a}}$ & - & - & - & - \\
\hline Morisssons & 0.15 & - & $0.4^{\mathrm{i}}$ to $1.4^{\mathrm{j}}$ & $0.39^{h}$ to $0.67^{i}$ & $0.22^{\mathrm{h}}$ \\
\hline Sainsbury & $0.085^{g}$ to $0.24^{f}$ & $0.38^{i}$ & $0.5^{\mathrm{c}}$ to $0.57^{\mathrm{h}}$ & $0.5^{\mathrm{c}}$ to $1.5^{\mathrm{j}}$ & $0.33^{\mathrm{e}, \mathrm{h}, \mathrm{k}}$ \\
\hline Asda & $0.13^{\mathrm{b}}$ to $0.33^{1}$ & $0.33^{i}$ & 0.49 & $0.47^{\mathrm{h}}$ to $0.87^{\mathrm{o}}$ & $0.27 \mathrm{p}$ to $0.75 \mathrm{q}$ \\
\hline Range ( $($ /litre) & 0.085 to 0.35 & 0.33 to 1.0 & 0.4 to 1.4 & 0.39 to 1.5 & 0.22 to 0.75 \\
\hline
\end{tabular}

${ }^{\mathrm{a}} 1 \mathrm{~L} \mathrm{bottle}^{\mathrm{b}} 4 \times 1 \mathrm{~L} \mathrm{multipack}^{\mathrm{c}} 6 \times 1 \mathrm{~L}$ multipack; ${ }^{\mathrm{d}} 10 \times 500 \mathrm{~mL}$ multipack; ${ }^{\mathrm{e}} 12 \times 500 \mathrm{~mL}$ multipack $^{\mathrm{f}} 10 \times 1 \mathrm{~L}$ multipack; ${ }^{\mathrm{g}}$ Hubards-2 L (sparkling); ${ }^{\mathrm{h}} 6 \times 1.5 \mathrm{~L}$ multipack; ${ }^{\mathrm{i}} 1.5 \mathrm{~L}$ bottle; ${ }^{\mathrm{j}} 500 \mathrm{~mL}$ bottle; $4 \times 2 \mathrm{~L}$ multipack; ${ }^{\mathrm{k}} 24 \times 500 \mathrm{~mL}$ multipack; ${ }^{1} 6 \times 750 \mathrm{~mL}$ multipack; ${ }^{\circ} 4 \times 750$ mL multipack; $\mathrm{P} 6 \times 1.5$ L multipack; ${ }^{q} 8 \times 250 \mathrm{~mL}$ multipack; ${ }^{\mathrm{r}} 750 \mathrm{~mL}$ bottle.

Hence the range of pricing shown in Figure 10 for bottled water is not inappropriate and suggests that students are far more aware of the cost of bottled water than of mains water. This is as expected, due to greater exposure via everyday interactions buying bottled water as compared to mains water [24,82]. Figure 12 shows that of those with the lowest price perception for mains water (i.e., $1-25$ pence) only $6 \%$ of these were able to correctly estimate water use (taken as 100 to $150 \mathrm{~L}$ ), with the remainder either underestimating (39\%) or overestimating $(55 \%)$ water use.

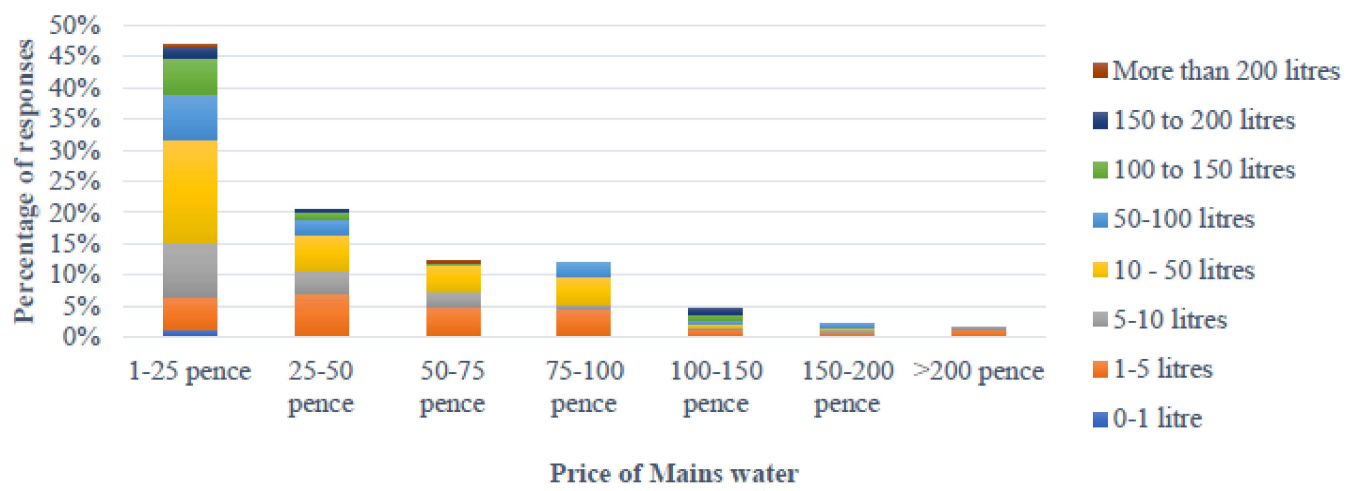

Figure 12. Perceptions of Mains Water Price and Water Use.

\subsection{Water Saving}

Q10-Which of the following Options Do You Think Would You Prefer When Considering Reducing Your Personal Water Consumption?

Given a choice of five options, students were asked to identify their preferred option for reducing personal water consumption (Figure 13). 


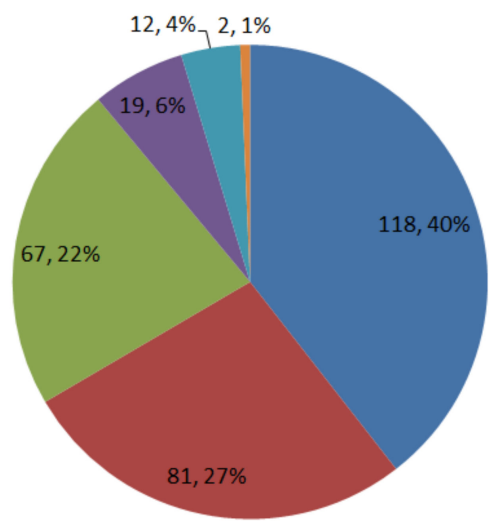

All

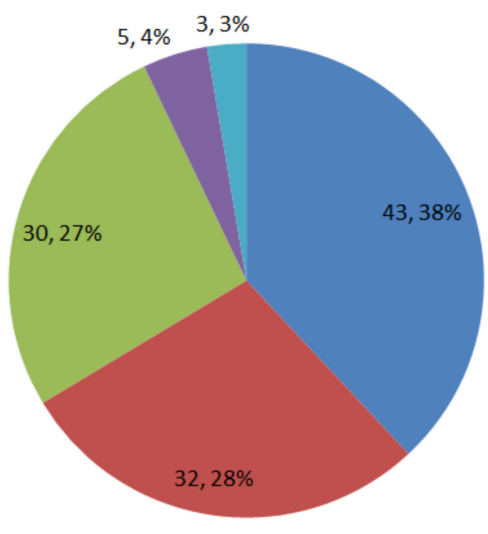

Female

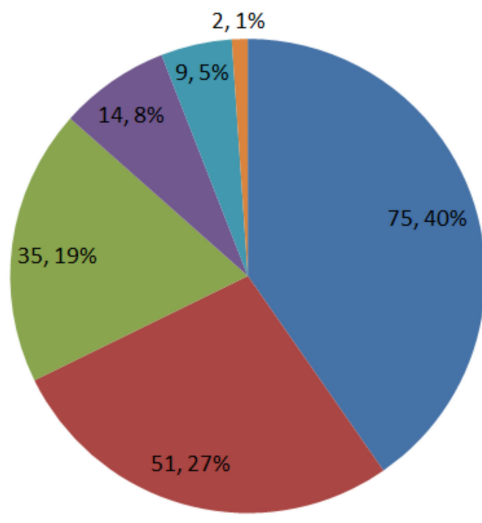

Male

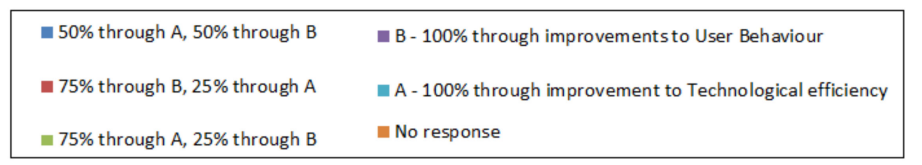

Figure 13. Preferences to Curtailment or Technology adoption.

Herein it can be seen that very few students ( $6 \%$ and $4 \%$ respectively) opted for either changing User behavior (Option A) alone or adopting efficient technologies (Option B) alone. For UK cohorts, this result agrees with surveys of general UK population which found that the willingness of 18-24 year olds to try water-saving devices was the highest [80]. Moreover, the findings agreed with the general trend of younger people leaning towards efficiency approaches [52].

An overall general trend, with $40 \%$ of the cohort opting for this strategy, was towards a balanced 50-50 approach between efficiency and curtailment. An approximately equal proportion (i.e., $22 \%$ vs. $27 \%$ respectively) had a preference for mostly technological or mostly curtailment, respectively. Overall, a wide variety of approaches were preferred. A marginal gender imbalance was found in all choice options, and although these results have to be statistically tested for significance, they appear to agree with Gholson et al. [51], who found gender to be a significant predictor with respect to adopting new water-saving technologies, with males in particular being more favorable toward this choice.

\section{Discussion}

\subsection{Introduction}

This Section discusses the implications of the survey findings, situating the issues and solutions within the broader theoretical frameworks explored in Sections 3.1-3.4 Herein both the grey literature and survey results suggest a novel approach to water conservation research and understanding (not least amongst MSc students) is required to enable more effective water conservation interventions.

\subsection{Water Use: Application of Practice Theory}

Results demonstrate that MSc students are generally aware which activities use the most water (i.e., showers and toilet flushing), with a generally accurate perception of shower durations and flushing frequency but greatly underestimate overall water use, by a factor of four on average. This suggests that MSc students can generally recognize water use practices with the highest potential for water savings. The majority of MSc students $(92 \%)$ did not have accurate water use perceptions, which is concurrent with the nationally representative survey in 2015 where $85 \%$ of respondents did not know their water use to any level of accuracy, showing a lack of understanding (i.e., awareness, perception) of their water consumption behavior [80,81]. 
Although promoting individual awareness and concern is a priority in the ABC-based model (Figure 1), there is a noted lack of prioritization of water conservation at an international level, such as the 2016 Paris Agreement [4], and when present water conservation literature features 'attractiveness and power' of 'behavioral changes driven by information provision' at an international level [34]. Many studies support the suggestion that awareness of actual individual water consumption will lead to water use savings [52,82,83], with the implicit knowledge-to-action rational behavioral pathway following the Ajzen model $[28,53]$. However, it is evident from other environmental challenges such as climate change that receiving relevant information 'does not guarantee appropriate action by the individual' [25]. This may partly explain why research finds that many of the previous efforts have not had a substantial impact on encouraging conservation behaviors [59] and reducing household water use [60]. This emphasizes the need for alternative models of understanding beyond individual information provision by considering individuals as an integral part of their social, cultural and historical settings [59]. Social Practice Theory offers a promising solution by considering complex socio-technical systems in a more rounded approach (see Figure 2) by decentralizing individuals to focus the investigation on routines and key elements reinforcing current practices.

Moreover, individual behavioral change-acting 'autonomously' in order to adapt to climate change, as a result of a single 'salient' event such as an intervention-is limiting. The Governmental role should be set more broadly in order to include the provision of incentives and coordination [69]. There is recognition of the difficulty in introducing policies for sustainable resource management but there is a pressing need for 'increased government action to align the incentives of individuals with society to limit climate change' [69].

Surprisingly, the current survey found that engineering MSc students greatly underestimated water use despite higher numeracy, contrasting with existing research [84]. This result could be a corollary of inattention due to marginal water prices (see Section 5.3), which suggests that a wider social norm and meaning related to water must change from abundant commodity to a precious resource for greater social prominence. Incorporating 'new pro-environmental meanings, skills and stuff ... into normal working life.' can lead to 'subtle shifts in elements of practice' to achieve 'broader transformation' that are needed [84]. A central role of the 'social dynamics of practice is often underplayed' in conventional and social practice theory approaches [55], leading to trends where environmental impacts of water use are not taken into account $[6,50,85]$. Nonetheless, the power of social norms and social actors in stimulating wide social changes can be indicated by the success of media coverage through societal prominence [86]. Heavy media attention highlighting the need for water conservation, which is linked to public attention, has been shown to result in an 11-18\% reduction in water use [65]. Additionally, the effectiveness of publicity, community-based programs and water conservation education are emphasized as key ways to achieve water savings $[52,87,88]$. This is true of postgraduate students and very much requires the creation of a society where water is valued; education at a younger age may play a significant role, as younger children are more responsive to environmental attitudes [89] where active forms of learning are more effective [68]. After all, when it comes to the environment, as the ESRC notes, education effects our actions [21,44]. The University of Birmingham, as with others across the UK, very much has sustainability at its heart and therefore research such as this begins to scratch the surface of whether such an ethos ultimately instills sustainable behavior in students; further research and insights in this area should be sought.

Framed by a practice theory perspective, water use practices are emphatically reliant on being in harmony with other routine practices within the home. Alternative research methods and educational programs are required, such as effective use of a diary for collective residential water usage data rather than individual estimates [24]; these offer greater opportunities to discover important inter- and intra-relationships 'between whole bundles of practice that co-exist in particular domains of everyday life' [55]. For example, a practice memory scrapbook has been demonstrated to be a useful qualitative method in 
further engaging and uncovering everyday normative practices involved in meanings, materials and skills [90]. Where students in this research identified what they actually used as compared to what they thought they used, significant discrepancies were apparent; students typically underestimated their water use. Further research into this area would be required to identify whether this is the case for all student cohorts and the population as a whole.

\subsection{Pricing}

There were largely accurate perceptions of the low cost of mains water pricing compared to bottled water. However, this was accompanied by a vast underestimation of overall water use, which suggests that pricing (certainly at current rates) is not central to the water use practice of students. The results of this study are consistent with existing UK-based studies where MSc students demonstrated a lack of knowledge of their own water tariffs and consumption [34,91]. The UK's temperate climate and small water bills for an unmetered water supply may be a factor in demonstrated 'weak engagement' of water customers [6,34]. This may point to an underlying consumer meaning of water scarcity as a socially produced scarcity rather than an absolute one, consequently relegating the burden of behavioral change to the unknown future. This attitude seems to be corroborated by the water companies, who seek to make a profit from offering assured secure supplies at all times in part to drive up sales [35], but also to ensure residents' rights to access clean water supplies are met.

Increasing block tariffs (IBT) as economic incentives are presented as a possible solution by authors [54] and are already successfully implemented by Hungary and Germany. However, trials have shown insufficient behavioral change, possibly due to insufficient price differentials [54]. Raising water prices is not only politically difficult [54,92]; IBT is also likely to further stress the lower-income groups unfairly from a social equity, water justice [93] and human rights perspective unless regulatory roles are carried out satisfactorily [54]. Moreover, higher-level income households are less perceptive to price changes despite being higher water consumers [94], making price changes less effective [88].

Some empirical evidence following the $\mathrm{ABC}$ framework supports curtailment driven by individual pro-environmental attitudes rather than pricing or demographics [95], with recent research suggesting nudges may be effective even in absence of pricing [38]. However, the rational linear model of behavior [15-17] may not effectively apply to residential water use as water users are 'rationally inattentive', using simple heuristics to judge water bills' accuracy due to the marginal cost of water [96], and making attitudinal change harder to achieve. Following the practice theory approach, wider social practice changes may contribute to conservative practices regardless of individual attitudes and beliefs [55]. As survey results show, water use perceptions are underestimated and undervalued, therefore social interactions may be the pivotal change needed within the UK context for effective water conservation. Research suggests that residential users are 'primarily responding to social comparisons due to increased salience of the moral cost of water consumption' [38].

In essence, application of social dynamics using social practice theory (SPT) may also enable greater understanding and buy-in towards pricing strategies.

\subsection{Water Conservation Approaches}

\subsubsection{Technology Efficiency vs. Curtailment}

Technological efficiency has been researched more extensively than curtailment, probably due to easier implementation through single events as compared to 'willpower' associated with curtailment [5]. While results indicate that the majority of MSc students favor a 50:50 approach, the reality might be different. From a practice theory perspective, substitution in things or technology is found to be easier than reconfigurations of existing practices [55]. Individual financial incentives and payback periods are often quoted in the drive to continually upgrade appliances [70], but the implications for the wider systems are ignored as technology efficiency cannot be seamlessly 'substituted into the 'social tissue" 
without changing the system 'substantially and unpredictably' [42]. Over-reliance on technology by both MSc students and the wider population may lead to the rebound effect that Labanca and Bertoldi [35] demonstrate with respect to energy using SPT, where improved efficiency may lead to higher use thereby driving even higher final consumption. Qualitative changes can offset the reductions achieved by technological efficiency $[42,67,68,92]$. In terms of water conservation, the perception that air-flow regulators enable water savings may influence behavior to inadvertently use showers for longer [97], hence strategies relying overly on technological evolution may face adverse unintended consequences. There is a distinctive societal norm of valuing 'needs' and 'wants' with the same level of importance, and both are generally used as benchmarking requirements in studies in this area [31]. Aspects of needs and wants for water as well as other resources have provoked a good level of discussion within all MSc cohorts over the years, not least with respect to the stark differences between developed and developing countries; these mirrored larger debates within the sustainability agenda.

For example, international agreements such as the 2016 Paris Agreement are often criticized as being heavily dependent on technological advancement and counterproductive due to the meanings of service conveyed by these interventions [98], as 'self-fulfilling conventions of need and entitlement are tacitly buried in plans and strategies' [47,48]. A key implicit understanding of policymakers that efficiency must not 'constrain or limit the multiplication of human activities, this limitation representing a potential threat for economic growth and social well-being' [35], thus purely efficiency-based solutions may act to preserve the current standards of living and 'help perpetuate unsustainable ways of life' [48]. This approach is found, naturally, to be ineffective in the long-term [99]. Lack of flexibility in the UK regarding our current quality of life and future aspirations [47] mean that standards inherently lead towards a more technological efficiency approach to water conservation [47]. Therefore, it is argued that the problem definition of water conservation must be reframed to enable a more holistic and effective approach to water conservation i.e., through a greater appreciation of such aspects as the water energy-food nexus [100-103].

\subsubsection{Smart Meters}

Smart meters are presented as a modern necessity or 'essential enablers' for improved measurement and management of urban potable water supply systems [70], with some studies finding reduced water use with the implementation of smart water meters [104,105]. However, widespread household water metering does not currently exist in the UK [61], thus this approach faces challenges as a practical solution. Research into consumer feedback technology is largely based on the ABC framework, particularly developments in smart metering technologies with individualized feedback mechanisms. As part of the ABC framework this helps with raising awareness of students and the public alike to their water use. Therein it would be hoped that this would incentivize changes in behavior, leading to a step change (reduction) in water use. There is a logical rationale here, and studies do imply that monitoring consumption of water will allow customers to control their consumption directly [106]. However, studies have also shown that hourly consumption of water through shower use data made no significant difference in demand for consumers; moreover, it led to them adopting more energy-efficient alternative appliances such as electric showers [107] which may partly be explained by qualitative or practical changes in the system [42]. Thus, the behavior incentivized was not to reduce showering time, as one might expect, but to seek a technological efficiency route-both of these being considered as options in the survey presented in this paper.

Lima and Navas [107] specify the need for 'involved and active clients', arguing that efforts in encouraging 'conscious' use of water need to be supported by a wider behavioral change with respect to water conservation in order to be able to take full advantage of smart metering. Also, while social practice theory recognizes the usefulness of contextualizing national environmental conservation aims to the local context in refocusing individual impact on water use and 'making it real and relevant' [55,108], it also cautions against 
'excessively individualistic measures' [48]. This may partly explain ineffective responses to the detailed feedback found in the Home Water Update study [108]. Thus, SPT considers technology as things with dynamic socio-technical interlinks with other practices and not merely as another decision-making factor, giving greater credence to the material and infrastructure contexts as compared to dominant models [55]. At the same time, the importance of social prominence and justice cannot be disregarded in setting the benchmarks and standards as part of meanings.

\subsubsection{Curtailment}

Just as water conservation is recognized as a cheaper and more time-efficient method of satisfying growing water demand compared to constructing new water supplies [31], curtailment has been widely recognized for cost saving as well as wider 'indirect costs for the energy requirement to treat, pump and maintain the water supply network' [31]. Water conservation based on curtailment can be quickly implemented without heavy infrastructure investments [20]. Research demonstrates that total residential demand or peak shift can lead to cost savings for water supply companies [31], with additional savings of up to $10 \%$ per household if cold water wastage is reduced [109]. Some technologies can be less acceptable due to user perception, for example, very low $1.5 \mathrm{~L}$ flush toilets or low flow showers [79]. However, as technology reaches and passes saturation point [20] curtailment is predicted to play a dominant role in achieving long-term 'persistent' reductions in water demands, due to ever growing populations [79]. In line with the earlier $A B C$ framework (Figure 2), communication aimed at curtailment is a key part of reducing water consumption. Moreover, it can be portrayed as playing a key role in overcoming (i.e., offsetting) the unexpected changes in behavior [110] discussed in Section 4.2. The key to the ABC framework is in how we make this transition - through the path of least resistance- either nudging students or adopting rational pathways with improvement in student knowledge, awareness, attitude and motivation. Some combination of the two is likely. Again, further research is needed to see which works best for student cohorts.

\subsubsection{Combined Solution Advantages}

Results from this current study showed that MSc students have a preference for a 50:50 combination of efficiency (technological) and curtailment when considering approaches to water conservation. This agrees with the widely supported view of a combined solution of both curtailment and adopting water-efficient technology as being indispensable for reducing water demand $[5,20,34,52]$. For example, improvements largely based on nudged curtailments for students (for example, push button controls for showers, incentivizing reduced shower duration, not running tap water while brushing teeth, waiting for a full washing load, rinsing dishes in tubs) in combination with using water efficient technologies (installing water-efficient washing machines and showerheads) are suggested [31]. Using a futures framework, a UK based study found that altering user behavior or technological efficiency measures separately only led to a $55 \%$ reduction in domestic water consumption per capita, compared with an $80 \%$ reduction when both approaches are combined [31]. This is supported by other studies showing that largely behavioral improvements range from $18.6-53.0 \%$ savings in water consumption [70].

Technology can help curtailment, making the dynamic nature of technology-curtailment relationship difficult to categorize decisively (i.e., by setting timers for showering or detecting leaks and repairing them [84]), and feedback through smart metering can be used to raise awareness for water conservation [109], making its use complementary in many ways. In line with the $A B C$ framework for changing behavior, a similar type of approach would be needed for changing and improving technological efficiency that householders or student landlords invest in, either through a reasoning or intuition pathway-in some ways a carrot or stick approach. 


\subsubsection{Educational Merits of the Survey}

The purpose of the survey was to engage students with the topic of sustainable water use practices. MSc students were shown their results and those of previous years as a precursor to opening up discussion on perceived vs. actual behavior. As a follow up to the course, in all of the five years students were asked to highlight key aspects of the course that helped them with understanding and engaging with the topic of sustainability. Repeatedly, students highlighted the survey as being a key component of this, not least in raising awareness of their own water using habits and knowledge. In this way, it can be deemed to have been successful and has shown to provide a key to opening up minds to engage with the topic of sustainable resource consumption. Hence it has not prompted a change in teaching, but it could be argued that the lack of awareness shown in MSc students might prompt its use at an earlier stage of undergraduate education.

\section{Recommendations}

Based on the research that has been undertaken here, both qualitative and quantitative elements of this study emphasize the importance of de-centralizing the individual to overcome the problem in current water conservation research. Evidence suggests a number of key recommendations:

- $\quad$ Social Practice Theory (SPT): Adoption of a novel theoretical SPT framework could be a key requirement in broadening study scopes to find more effective ways of reducing water demand. Further research is needed for practical application of an SPT approach, particularly in meanings and how changing our unit of understanding can help water conservation efforts, taking lessons from the more advanced energy and health sectors. In understanding water conservation as a practice theory problem, the links between the different bundles of practices must be examined holistically to find elements enabling its renewal before the practice can be effectively challenged and reformed in more sustainable ways [55].

- Semi-Structured Interviews and Case Studies: Although the online survey of students has served its purpose in assessing the level of awareness of MSc students, semistructured interviews and case studies are more appropriate to discover perceptions and find emerging socially constructed patterns of water use $[53,55,111,112]$. For example, it would be interesting to explore perceptions of individual water use habits of students (MSc and undergraduate) through interviews following an initial perception survey and monitored usage via smart meters.

- Longitudinal Studies: Although the present study contributes to the gap, larger samples of more longitudinal studies on individual-level perception inaccuracies are needed. More accurate water usage data on students is also needed, inclusive of water-use diaries, to enable comparison between international students in other schools both within the University of Birmingham and at other universities. Using water use practices as the unit of analysis enables research on approaching customers based on their water use practices that would be valuable for the water industry and future governmental policies.

- Efficacy of water-saving education: Studies are needed to investigate the effectiveness of water-saving education programs in other universities and how this corresponds to actual water savings, either through monitoring water demand or using a diary to discover links of practices to offer more effective intervention opportunities, which also allows an opportunity to investigate trust in information sources and our social understanding of water.

Weak engagement of water users due to lack of national and international attention, paired with self-fulfilling standards and policies, may explain the ineffectiveness of current approaches. A more central role for social dynamics using social media with supported early education and societal prominence beyond the monetary value of water is a promising solution. Cost-effective methods such as making water-conservation a part of the schooling system and community-based programs with an emphasis on the water-energy-food nexus 
and conservation of our natural resources may enable increased buy-in from the public on other approaches with respect to pricing and conscious use of technology. Using water use practices as our central unit of analysis and redefining the problem with a greater appreciation of sociotechnical effects may be the key to reducing water demand in the long-term. Thus, a more holistic, multi-modal approach, informed by practice theory based research is needed at different levels of policies and initiatives in order for water conservation practices to emerge as a part of the fabric of a modern urban lifestyle.

\section{Conclusions}

Key Findings

To conclude, this study has successfully enlarged upon the current issues in residential water conservation of MSc students, analyzing key themes and approaches for achieving water savings through survey results together with available grey literature, to suggest Social Practice Theory (SPT) to be a more effective means of approaching water conservation for students in the UK. This research contributes to perception studies, which are lacking as few have been done in individual-level water conservation, with almost none in the further education cohort. The survey investigated the individual level of awareness and perceptual inaccuracies of water use habits and price to uncover issues with the current societal prominence awarded to water. The key findings are that on average, Masters level students:

- Underestimate their water use compared to the national average, by a factor of approximately four;

- Have a high general awareness of high water use activities, with perceptions of showering and toilet flushing frequency being comparable to national estimates;

- Have inaccurate perceptions of water use which, moreover, are highly influenced by country of birth;

- Are well aware of the cost disparity between mains and bottled water cost, however they are more aware of the cost of bottled water $(47 \%$ of students correctly estimated mains water price within $25 \%$ accuracy, compared to $58 \%$ for bottled water);

- Have a preference ( $89 \%$ of MSc students) for some kind of combined approach (as between technological efficiency and curtailment) to reduce personal water use. This indicates that they are likely to respond positively and adopt water-conservation behaviors given the correct encouragement and education.

Results were shown to be comparable to a number of existing studies and national averages, reinforcing both the relevance and reliability of the approach.

This study further advocates that:

- Current individual-focused policies and industry initiatives using pricing approaches and via smart metering have had limited impact. Moreover, increasing the marginal mains water prices in the UK may be politically difficult and ineffective due to a lack of rationally attentive water users;

- Survey results support the conclusion that information-based interventions are not leading to effective awareness or overcoming the value-action gap. A possible overgearing towards technological efficiency could be due partially to an implicit view towards preserving the current lifestyle and standards, generally finding alternative technology at a higher economic cost to be preferable to changes in practice. It is proposed that the wider socio-technical context of water use practices must change in its meanings from abundant commodity to precious resource in order for greater social prominence to encourage water conservation practices;

- Current perceptions of water abundance in the UK are likely to result in greater risk of water scarcity and associated problems compared to other developed countries, which are taking notice of and prioritizing water conservation and using alternative strategies in response to growing population and climate change pressures. 
Author Contributions: Abstract and Introduction, D.V.L.H. and Z.S.; Methodology, D.V.L.H. and Z.S.; Main body of research with Analyses and Results, D.V.L.H. and Z.S.; Discussion, D.V.L.H. and Z.S.; Conclusions, D.V.L.H. and Z.S.; Writing-original draft preparation, D.V.L.H.; Supervision, revision, editing, and proofreading, D.V.L.H. Both authors have contributed to the work reported. All authors have read and agreed to the published version of the manuscript.

Funding: D.V.L.H. received the financial support of the UK EPSRC under grant EP/J017698/1 (Transforming the Engineering of Cities to Deliver Societal and Planetary Wellbeing, known as Liveable Cities) and EP/P002021 (From Citizen to Co-innovator, from City Council to Facilitator: Integrating Urban Systems to Provide Better Outcomes for People, known as Urban Living Birmingham).

Institutional Review Board Statement: Ethical review and approval was obtained from the University of Birmingham Ethical Committee.

Informed Consent Statement: Written informed consent has been obtained from the participants to publish this paper.

Data Availability Statement: The data presented in this study are not publicly available due to privacy, confidentiality and ethical reasons.

Acknowledgments: The authors gratefully acknowledge the voluntary participation of the students from the Sustainable Construction module at the University of Birmingham.

Conflicts of Interest: The authors declare no conflict of interest.

\section{References}

1. United Nations, Department of Economic and Social Affairs, Population Division. World Population Prospects: The 2017 Revision; United Nations: New York, NY, USA, 2017; Volume 33, pp. 1-66.

2. United Nations, Department of Economic and Social Affairs, Population Division. World Urbanization Prospects: The 2014 Revision; United Nations: New York, NY, USA, 2015.

3. United Nations, Department of Economic and Social Affairs, Population Division. World Urbanization Prospects; United Nations: New York, NY, USA, 2019; Volume 12, ISBN 9789211483192.

4. UNESCO Digital Library. The United Nations World Water Development Report 2020: Water and Climate Change. 2020. Available online: unesdoc.unesco.org/ark:/48223/pf0000372985.locale=en (accessed on 7 May 2021).

5. Koop, S.H.A.; Van Dorssen, A.J.; Brouwer, S. Enhancing domestic water conservation behaviour: A review of empirical studies on influencing tactics. J. Environ. Manag. 2019, 247, 867-876. [CrossRef]

6. DEFRA. Public Understanding of Sustainable Water Use in the Home: A Report to the Department for Environment, Food and Rural Affairs; The Stationery Office: London, UK, 2009.

7. Ofwat. PR19 Final Determinations: Strategic Regional Water Resource Solutions; Ofwat: Birmingham, UK, 2019.

8. DEFRA. Future Water: The Government's Water Strategy for England. A Report to the Department for Environment, Food and Rural Affairs; The Stationery Office: London, UK, 2008.

9. ONS-Office of National Statistics 2018. Consumption Per Head in the UK. 2017. Available online: https:/ /www.ons.gov.uk/ economy/inflationandpriceindices/bulletins/consumptionperhead/2018 (accessed on 10 May 2021).

10. Holdsworth, S.; Kenny, D.; Cooke, J.; Matfin, S. Are we living with our heads in the clouds? Perceptions of liveability in the Melbourne high-rise apartment market. In Energy Performance in the Australian Built Environment; Rajagopalan, P., Andamon, M.M., Moore, T., Eds.; Springer: Singapore, 2019; pp. 181-198. ISBN 978-981-10-7879-8.

11. Norouzian-Maleki, S.; Bell, S.; Hosseini, S.-B.; Faizi, M.; Saleh-Sedghpour, B. A comparison of neighbourhood liveability as perceived by two groups of residents: Tehran, Iran and Tartu, Estonia. Urban For. Urban Green. 2018, 35, 8-20. [CrossRef]

12. Hopkinson, P.; Hughes, P.; Layer, G. Sustainable graduates: Linking formal, informal and campus curricula to embed education for sustainable development in the student learning experience. Environ. Educ. Res. 2008, 14, 435-454. [CrossRef]

13. Chaplin, G.; Wyton, P. Student engagement with sustainability: Understanding the value-action gap. Int. J. Sustain. High. Educ. 2014, 15, 404-417. [CrossRef]

14. Karp, D.G. Values and their Effect on Pro-Environmental Behavior. Environ. Behav. 1996, 28, 111-133. [CrossRef]

15. Topal, H.F.; Hunt, D.V.; Rogers, C.D. Urban Sustainability and Smartness Understanding (USSU)—Identifying influencing factors: A systematic review. Sustainability 2020, 12, 4682. [CrossRef]

16. Topal, H.F.; Hunt, D.V.; Rogers, C.D. Exploring urban sustainability understanding and behaviour: A systematic review towards a conceptual framework. Sustainability 2021, 13, 1139. [CrossRef]

17. Topal, H.F.; Hunt, D.V.; Rogers, C.D. Sustainability understanding and behaviors across urban areas: A case study on Istanbul City. Sustainability 2021, 13, 7711. [CrossRef]

18. Larbey, R.; Weitkamp, E. Water Scarcity Communication in the UK: Learning From Water Company Communications Following the 2018 Heatwave. Front. Environ. Sci. 2020, 8, 578423. [CrossRef] 
19. Shafiei, A.; Maleksaeidi, H. Pro-environmental behavior of university students: Application of protection motivation theory. Glob. Ecol. Conserv. 2020, 22. [CrossRef]

20. Moglia, M.; Cook, S.; Tapsuwan, S. Promoting Water Conservation: Where to from here? Water 2018, 10, 1510. [CrossRef]

21. Adams, D.C.; Allen, D.; Borisova, T.; Boellstorff, D.E.; Smolen, M.D.; Mahler, R.L. The Influence of Water Attitudes, Perceptions, and Learning Preferences on Water-Conserving Actions. Nat. Sci. Educ. 2013, 42, 114-122. [CrossRef]

22. Cape, P.; Phillips, K. Questionnaire Length and Fatigue Effects: The Latest Thinking and Practical Solutions. White Paper. 17 pages. 2015. Available online: https:/ / silo.tips/download/white-paper-questionnaire-length-and-fatigue-effects-the-latestthinking-and-pra (accessed on 31 June 2021).

23. Revilla, M.; Ochoa, C. Ideal and maximum length for a web survey. Int. J. Mark. Res. 2017, 59, 557-565.

24. O'Toole, J.; Sinclair, M.; Leder, K. Collecting household water usage data: Telephone questionnaire or diary? BMC Med. Res. Methodol. 2019, 9, 72.

25. Pearce, R.; Dessai, S.; Barr, S. Re-Framing Environmental Social Science Research for Sustainable Water Management in a Changing Climate. Water Resour. Manag. 2013, 27, 959-979. [CrossRef]

26. De Leeuw, A.; Valois, P.; Ajzen, I.; Schmidt, P. Using the theory of planned behavior to identify key beliefs underlying proenvironmental behavior in high-school students: Implications for educational interventions. J. Environ. Psychol. 2015, 42, 128-138. [CrossRef]

27. Kaplan, S. New Ways to Promote Proenvironmental Behavior: Human Nature and Environmentally Responsible Behavior. J. Soc. Issues 2000, 56, 491-508. [CrossRef]

28. Ajzen, I. From intentions to actions: A theory of planned behavior. In Action Control: From Cognition to Behaviour; Kuhi, J., Beckmann, J., Eds.; Springer: Berlin/Heidelberg, Germany, 1985; pp. 11-39.

29. Gilbertson, M.; Hurlimann, A.; Dolnicar, S. Does water context influence behaviour and attitudes to water conservation? Australas. J. Environ. Manag. 2011, 18, 47-60. [CrossRef]

30. Shove, E.A. Beyond the ABC: Climate Change Policy and Theories of Social Change. Environ. Plan. A Econ. Space 2010, 42, 1273-1285. [CrossRef]

31. Zadeh, S.M.; Hunt, D.V.; Rogers, C.D. Socio-Technological Influences on Future Water Demands. Water 2014, 6, 1961-1984. [CrossRef]

32. De Haan, F.J.; Ferguson, B.C.; Deletic, A.; Brown, R. A socio-technical model to explore urban water systems scenarios. Water Sci. Technol. 2013, 68, 714-721. [CrossRef] [PubMed]

33. Mao, F.; Khamis, K.; Clark, J.; Krause, S.; Buytaert, W.; Ochoa-Tocachi, B.F.; Hannah, D.M. Moving beyond the Technology: A Socio-technical Roadmap for Low-Cost Water Sensor Network Applications. Environ. Sci. Technol. 2020, 54, 9145-9158. [CrossRef]

34. Lu, L. Information-based interventions for household water efficiency in England and Wales: Evidence, barriers and learning opportunities. Int. J. Water Resour. Dev. 2020, 36, 926-939. [CrossRef]

35. Kallis, G. Droughts. Annu. Rev. Environ. Resour. 2008, 33, 85-118. [CrossRef]

36. Ofwat. Push, Pull, Nudge-How Can We Help Customers Save Water, Energy and Money? Ofwat Report; Ofwat: Birmingham, UK, 2011.

37. Lodge, M.; Wegrich, K. The Rationality Paradox of Nudge: Rational Tools of Government in a World of Bounded Rationality. Law Policy 2016, 38, 250-267. [CrossRef]

38. Brent, D.A.; Wichman, C.J. Do Behavioral Nudges Interact with Prevailing Economic Incentives? Pairing Experimental and Quasi-Experimental Evidence from Water Consumption, LEMA Seminar, Pennsylvania State University. Unpublished Work in Progress. 2020. Available online: https:/ / www.semanticscholar.org/paper/Do-behavioral-nudges-interact-with-prevailingand-Brent-Wichman/2b0a22b2543d9b37f750530fc5366d72b266ec3b?p2df (accessed on 8 May 2020).

39. Thaler, R.H.; Sunstein, C.R. Nudge: Improving Decisions About Health, Wealth and Happiness; Yale University Press: New Haven, CT, USA, 2008.

40. Reddy, S.M.; Montambault, J.; Masuda, Y.J.; Keenan, E.; Butler, W.; Fisher, J.R.; Asah, S.T.; Gneezy, A. Advancing conservation by understanding and influencing human behavior. Conserv. Lett. 2017, 10, 248-256. [CrossRef]

41. Blake, J. Overcoming the 'value-action gap' in environmental policy: Tensions between national policy and local experience. Local Environ. 1999, 4, 257-278. [CrossRef]

42. Labanca, N.; Bertoldi, P. Beyond energy efficiency and individual behaviours: Policy insights from social practice theories. Energy Policy 2018, 115, 494-502. [CrossRef]

43. Satur, P.; Lindsay, J. Social inequality and water use in Australian cities: The social gradient in domestic water use. Int. J. Justice Sustain. 2020, 25, 351-364. [CrossRef]

44. Hampton, S.; Adams, R. Behavioural economics vs social practice theory: Perspectives from inside the United Kingdom government. Energy Res. Soc. Sci. 2018, 46, 214-224. [CrossRef]

45. Russell., S.; Fielding., K. Water demand management research: A psychological perspective. Water Resour. Res. 2010, 46. [CrossRef]

46. Lodge, M.; Wegrich, K. The Problem-solving Capacity of the Modern State: Governance Challenges and Administrative Capacities.; Oxford Scholarship Online: Oxford, UK, 2014.

47. Shove, E.; Pantzar, M.; Watson, M. The Dynamics of Social Practice; SAGE Publications: London, UK, 2012. 
48. Shove, E. Putting practice into policy: Reconfiguring questions of consumption and climate change. Contemp. Soc. Sci. 2014, 9 , 415-429. [CrossRef]

49. Plimmer, G. Ofwat Faces Biggest Battle with Water Companies Since Privatisation, Financial Times. 14 February 2020. Available online: https://www.ft.com/content/5da761e6-4f04-11ea-95a0-43d18ec715f5 (accessed on 3 July 2021).

50. Jorgensen, B.; Graymore, K.; O’Toole, K. Household water use behaviour: An integrated model. J. Environ. Manag. 2009, 91, 227-236. [CrossRef] [PubMed]

51. Gholson, D.M.; Boellstorff, D.E.; Cummings, S.R.; Wagner, K.L.; Dozier, M.C. A Survey of Public Perceptions and Attitudes about Water Availability Following Exceptional Drought in Texas. J. Contemp. Water Res. Educ. 2019, 166, 1-11. [CrossRef]

52. Beal, C.D.; Stewart, R.A.; Fielding, K. A novel mixed method smart metering approach to reconciling differences between perceived and actual residential end use water consumption. J. Clean. Prod. 2013, 60, 116-128. [CrossRef]

53. DEFRA. Water Efficiency and Behaviour Change Rapid Evidence Assessment (REA). DEFRA Research Project WT1562; DEFRA: London, UK, 2018.

54. Hunt, D.V.L.; Rogers, C.D.F. A Benchmarking System for Domestic Water Use. Sustainability 2014, 6, 2993-3018. [CrossRef]

55. Hargreaves, T. Practice-ing behaviour change: Applying social practice theory to pro-environmental behaviour change. J. Consum. Cult. 2011, 11, 79-99. [CrossRef]

56. Gram-Hanssen, K. Standby consumption in households analysed with a practice theory approach. J. Ind. Ecol. 2010, 14, 150-165. [CrossRef]

57. Halkier, B.; Jensen, I. Methodological challenges in using practice theory in consumption research. Examples from a study on handling nutritional contestations of food consumption. J. Consum. Cult. 2011, 11, 101-123. [CrossRef]

58. Kuijer, L. Implications of Social Practice Theory for Sustainable Design. Ph.D. Thesis, Delft University of Technology, Delft, The Netherlands, 2014. Available online: https:/ / studiolab.ide.tudelft.nl/studiolab/kuijer/thesis/ (accessed on 5 May 2020).

59. Moloney, S.; Strengers, Y. 'Going Green'?: The Limitations of Behaviour Change Programmes as a Policy Response to Escalating Resource Consumption. Environ. Policy Gov. 2014, 24, 94-107. [CrossRef]

60. Brown, P. Narrative: An ontology, epistemology and methodology for pro-environmental psychology research. Energy Res. Soc. Sci. 2017, 31, 215-222. [CrossRef]

61. Lu, L.; Deller, D.; Hviid, M. Price and behavioural signals to encourage household water conservation: Implications for the UK. Water Resour. Manag. 2018, 33, 475-491. [CrossRef]

62. Southerton, D.; Warde, A.; Hand, M. The limited autonomy of the consumer: Implications for sustainable consumption. In Sustainable Consumption: The Implications of Changing Infrastructures of Provision; Southerton, D., Chappells, H., van Vliet, B., Eds.; Edward Elgar: Cheltenham, UK, 2004; pp. 32-48.

63. Lindsay, P.H.; Norman, D.A. Human Information Processing: An Introduction to Psychology; Academic Press: New York, NY, USA, 1977.

64. Addo, I.B.; Thoms, M.C.; Parsons, M. The influence of water-conservation messages on reducing household water use. Appl. Water Sci. 2019, 9, 126. [CrossRef]

65. Quesnel, K.J.; Ajami, N.K. Changes in water consumption linked to heavy news media coverage of extreme climatic events. Sci. Adv. 2017, 3, e1700784. [CrossRef]

66. Economic and Social Research Council (ESRC). When It Comes to the Environment, Education Affects our Actions. Science Daily. ScienceDaily, 21 March 2011. Available online: https:/ / www.sciencedaily.com/releases/2011/03/110321093843.htm (accessed on 7 July 2021).

67. Manouseli, D. Evaluation of Residential Water Efficiency Programmes in the UK. Ph.D. Thesis, Loughborough University, Loughborough, UK, 2017.

68. Manouseli, D.; Kayaga, S.M.; Kalawsky, R. Evaluating the Effectiveness of Residential Water Efficiency Initiatives in England: Influencing Factors and Policy Implications. Water Resour. Manag. 2019, 33, 2219-2238. [CrossRef]

69. Larcom, S.; She, P.-W.; Van Gevelt, T. The UK summer heatwave of 2018 and public concern over energy security. Nat. Clim. Chang. 2019, 9, 370-373. [CrossRef]

70. Willis, R.M.; Stewart, R.A.; Panuwatwanich, K.; Williams, P.R.; Hollingsworth, A.L. Quantifying the influence of environmental and water conservation attitudes on household end use water consumption. J. Environ. Manag. 2011, 92, 1996-2009. [CrossRef] [PubMed]

71. STEM Women in STEM: Percentages of Women in STEM Statistics. 2020. Available online: https://www.stemwomen.co.uk/ blog/2021/01/women-in-stem-percentages-of-women-in-stem-statistics (accessed on 3 August 2021).

72. CLG_Code for Sustainable Homes (Technical Guide), Communities and Local Government. 2010. Available online: https:/ / assets.publishing.service.gov.uk/government/uploads/system/uploads/attachment_data/file/5976/code_for_ sustainable_homes_techguide.pdf (accessed on 4 August 2021).

73. Water UK. Water UK Public Polling: A Poll of UK Adults on Their Water Usage and Attitudes to Saving Water. August 2020. Available online: https:/ / comresglobal.com/polls/water-uk-public-polling-august-2020/ (accessed on 4 August 2021).

74. Zhang, W.; Du, X.; Huang, A.; Yin, H. Analysis and comprehensive evaluation of water use efficiency in China. Water 2019, 11, 2620. [CrossRef]

75. Press Release, Per Capita Availability of Water (In India). 2020. Available online: https:/ / pib.gov.in/PressReleasePage.aspx? PRID=1604871 (accessed on 4 August 2021). 
76. Singh, O.; Turkiya, S. A survey of household domestic water consumption patterns in rural semi-arid village, India. GeoJournal 2013, 78, 777-790. [CrossRef]

77. IWA. International Statistics for Water Services 2018 Information Every Water Professional Should Know. 2020. Available online: https:/ /iwa-network.org/wp-content/uploads/2018/10/IWA-2018-Statistics-Flyer-Web-ready-revised.pdf (accessed on 4 August 2021).

78. Butler, D. The influence of dwelling occupancy and day of the week on domestic appliance wastewater discharges. Build. Environ. 1991, 28, 73-79. [CrossRef]

79. Hunt, D.V.L.; Rogers, C.D.F. Rainwater harvesting: Trade-offs between pluvial flood risk alleviation and mains water resource savings. In Proceedings of the 4th World Sustainability Forum, Vienna, Austria, 1-3 November 2014; Volume 4, p. 1. [CrossRef]

80. Waterwise. Waterwise-Ideal Standard Water Efficiency Annual Tracker Survey Summary Report: A Water Saving Report. Waterwise. 2016, Volume 2. Available online: https:/ / www.waterwise.org.uk/wpcontent/uploads/2018/02/Annual-TrackerSurvey-Report-2016.pdf (accessed on 9 May 2020).

81. Gardner, K. Residential Water Demand Modelling and Behavioural Economics. Ph.D. Thesis, University of East Anglia, Norwich, $\mathrm{UK}, 2010$.

82. Fan, L.; Wang, F.; Liu, G.; Yang, X.; Qin, W. Public Perception of Water Consumption and Its Effects on Water Conservation Behavior. Water 2014, 6, 1771-1784. [CrossRef]

83. Corral-Verdugo, V.; Bechtel, R.B.; Fraijo-Sing, B. Environmental beliefs and water conservation: An empirical study. J. Environ. Psychol. 2003, 23, 247-257. [CrossRef]

84. Attari, S.Z. Perceptions of water use. Proc. Natl. Acad. Sci. USA 2014, 111, 5129-5134. [CrossRef] [PubMed]

85. DEFRA. Water Statistics in the UK: RED Technical Report WT1509. Department for Food and Rural Affairs-DEFRA Report 9945 B; DEFRA: London, UK, 2014.

86. Treuer, G.; Koebele, E.; Deslatte, A.; Ernst, K.; Garcia, M.; Manago, K. A narrative method for analyzing transitions in urban water management: The case of the Miami-Dade Water and Sewer Department. Water Resour. Res. 2017, 53, 891-908. [CrossRef]

87. Lee, M.; Tansel, B.; Balbin, M. Influence of residential water use efficiency measures on household water demand: A four year longitudinal study. Resour. Conserv. Recycl. 2011, 56, 1-6. [CrossRef]

88. Brown, R.R.; Keath, N.; Wong, T.H.F. Urban water management in cities: Historical, current and future regimes. Water Sci. Technol. 2009, 59, 847-855. [CrossRef]

89. Liefländer, A.; Bogner, F.X. The Effects of Children's Age and Sex on Acquiring Pro-Environmental Attitudes Through Environmental Education. J. Environ. Educ. 2014, 45, 105-117. [CrossRef]

90. Maller, C.; Strengers, Y. Studying social practices and global practice change using scrapbooks as a cultural probe. Area 2018, 50, 66-73. [CrossRef]

91. Waddams, C.; Clayton, K. Consumer Choice in the Water Sector. Centre for Competition Policy, University of East Anglia. 2010. Available online: https://www.ofwat.gov.uk/publication/consumer-choice-in-thewater-sector/ (accessed on 4 May 2020).

92. Olmstead, S.; Stavins, R. Comparing price and non-price approaches to urban water conservation. Water Resour. Res. 2009, 45. [CrossRef]

93. Shrimpton, E.; Hunt, D.; Rogers, C. Justice in (English) Water Infrastructure: A Systematic Review. Sustainability 2021, 13, 3363. [CrossRef]

94. Sant'Ana, D.; Mazzega, P. Socioeconomic analysis of domestic water end-use consumption in the Federal District, Brazil. Sustain. Water Resour. Manag. 2018, 4, 921-936. [CrossRef]

95. Willis, R.M.; Stewart, R.A.; Giurco, D.P.; Talebpour, M.R.; Mousavinejad, A. End use water consumption in households: Impact of socio-demographic factors and efficient devices. J. Clean. Prod. 2013, 60, 107-115. [CrossRef]

96. Wang, X.; Lee, J.; Yan, J.; Thompson, G.D. Testing the behavior of rationally inattentive consumers in a residential water market. J. Environ. Econ. Manag. 2018, 92, 344-359. [CrossRef]

97. Mayer, P.W.; de Oreo, W.B.; Opitz, E.M.; Kiefer, J.C.; Davis, W.Y.; Dziegielewski, B.; Nelson, J.O. Residential End Uses of Water; American Water Works Association: Denver, CO, USA, 1999.

98. Hodder, I. The Entanglements of Humans and Things: A Long-Term View. New Lit. Hist. 2014, 45, 19-36. [CrossRef]

99. Stewart, R.A.; Willis, R.M.; Panuwatwanich, K.; Sahin, O. Showering behavioural response to alarming visual display monitors: Longitudinal mixed method study. Behav. Inf. Technol. 2013, 32, 695-711. [CrossRef]

100. De Laurentiis, V.; Hunt, D.V.; Rogers, C. Contribution of school meals to climate change and water use in England. Energy Procedia 2017, 123, 204-211. [CrossRef]

101. De Laurentiis, V.; Hunt, D.V.; Rogers, C.D. Overcoming Food Security Challenges within an Energy/Water/Food Nexus (EWFN) Approach. Sustainability 2016, 8, 95. [CrossRef]

102. Palafox-Alcantar, P.G.; Lee, S.E.; Hunt, D.V.L.; Rogers, C.D.F. The Little Book of Circular Economies in Cities. 2018. Available online: http:/ /liveablecities.org.uk/sites/default/files/-outcome_downloads/littlebookofcirculareconomyincities-pdf (accessed on 2 July 2021).

103. Simpson, G.B.; Jewitt, G. The Development of the Water-Energy-Food Nexus as a Framework for Achieving Resource Security: A Review. Front. Environ. Sci. 2019, 7, 8. [CrossRef] 
104. Erickson, T.; Podlasek, M.; Sahu, S.; Dai, J.D.; Chao, T.; Naphade, M. The dubuque water portal: Evaluation of the uptake, use and impact of residential water consumption feedback. In Proceedings of the SIGCHI Conference on Human Factors in Computing Systems, New York, NY, USA, 5-10 May 2012; pp. 675-684.

105. Fielding, K.S.; Spinks, A.; Russell, S.; McCrea, R.; Stewart, R.; Gardner, J. An experimental test of voluntary strategies to promote urban water demand management. J. Environ. Manag. 2013, 114, 343-351. [CrossRef]

106. Kenney, D.S.; Goemans, C.; Klein, R.; Lowrey, J.; Reidy, K. Residential Water Demand Management: Lessons from Aurora, Colorado1. JAWRA J. Am. Water Resour. Assoc. 2008, 44, 192-207. [CrossRef]

107. Lima, C.A.F.; Navas, J.R.P. Smart metering and systems to support a conscious use of water and electricity. Energy 2012, 45, 528-540. [CrossRef]

108. Carboni, D.; Gluhak, A.; McCann, J.A.; Beach, T.H. Contextualising Water Use in Residential Settings: A Survey of Non-Intrusive Techniques and Approaches. Sensors 2016, 16, 738. [CrossRef]

109. Liu, A.; Giurco, D.; Mukheibir, P. Motivating metrics for household water-use feedback. Resour. Conserv. Recycl. 2015, 103, 29-46. [CrossRef]

110. Campbell, H.E.; Johnson, R.M.; Larson, E.H. Prices, Devices, People, or Rules: The Relative Effectiveness of Policy Instruments in Water Conservation1. Rev. Policy Res. 2004, 21, 637-662. [CrossRef]

111. Shove, E. What is wrong with energy efficiency? Build. Res. Inf. 2018, 46, 779-789. [CrossRef]

112. Zhen, N.; Rogers, S.; Barnett, J. Everyday practices and technologies of household water consumption: Evidence from Shanghai. Environ. Urban. 2018, 31, 231-248. [CrossRef] 